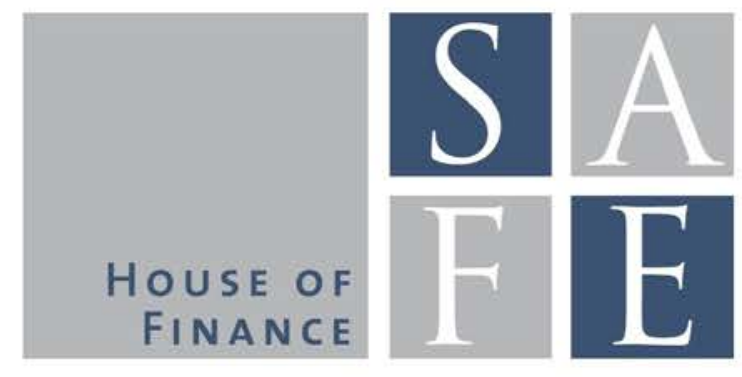

WORKING PAPER SERIES

Roberto C. Panzica

\title{
Idiosyncratic Volatility Puzzle: The Role of Assets' Interconnections
}

SAFE Working Paper No. 228

SAFE I Sustainable Architecture for Finance in Europe A cooperation of the Center for Financial Studies and Goethe University Frankfurt 


\section{Non-Technical Summary}

The network estimation based on the causality methodology is used to understand how the risk spreads across assets returns. Assuming that the idiosyncratic shocks move according to the channel defined by the network based on the Granger causality, the paper investigates if a relation by indegree centrality and stocks returns exists and if the risk factor based on the indegree explains the idiosyncratic volatility puzzle. The puzzle consists of observing empirically a negative relation between portfolios sorted by idiosyncratic volatility with respect to Fama and French (1993) at the previous month and the expected stock returns.

This association does not agree with the standard theory because the idiosyncratic risk can be diversified away and therefore should not be priced; moreover, it is not clear why the market should treat stocks having high idiosyncratic volatility as insurance. The basic idea of the paper is that interconnections can interfere with the aggregation mechanisms of idiosyncratic shocks as seen in chapter one. In this case, the network does not affect endogenously assets returns as previously. The work analyzes if indegree associated with the Granger causality could be seen as an exogenous factor. The analysis starts by replicating the results of Ang et al. (2006) and by using the same data and the same data period I investigate whether portfolio sorted by the indegree measure shows any relationship with stock returns. The study shows that there is a negative relationship between portfolios sorted by increasing indegree at previous month and stocks returns. This factor is largely negatively correlated with the momentum factor. Although the work does not explain the idiosyncratic volatility puzzle, i.e., the omitted factor that makes the alphas significant concerning Fama and French (1993) is not imputable to indegree. The second question I investigate is if portfolios having stocks with higher idiosyncratic volatility have lower or negative exposures on the factor based on indegree. Other centrality measures do not reveal the negative relation between stocks returns as indegree does. 


\title{
Idiosyncratic volatility puzzle: The role of assets' interconnections

\author{
Roberto C. Panzica ${ }^{\dagger}$
}

This version: August 8, 2018

\begin{abstract}
The paper investigates the determinants of the idiosyncratic volatility puzzle by allowing linkages across asset returns. The first contribution of the paper is to show that portfolios sorted by increasing indegree computed on the network based on Granger causality test have lower expected returns, not related to idiosyncratic volatility. Secondly, empirical evidence indicates that stocks with higher idiosyncratic volatility have the lower exposition on the indegree risk factor.
\end{abstract}

Keywords: Idiosyncratic volatility puzzle; Networks; Expected Returns; Granger Causality.

J.E.L. codes: G10 G12

${ }^{*}$ I gratefully acknowledge research support from the Research Center SAFE, funded by the State of Hessen initiative for research LOEWE.

${ }^{\dagger}$ Goethe University Frankfurt, Germany 


\section{Introduction}

Increasing literature investigates the role of the aggregate volatility risk and its relations with expected stocks returns. ${ }^{1}$ Ang et al. (2006) find that stocks with higher sensitivity to innovations in aggregate volatility have very low average returns, and at the same time stocks with high idiosyncratic risk have abysmally low average returns. The authors show that the change in aggregate volatility is a risk factor with a negative risk premium. ${ }^{2}$ They supposed that idiosyncratic volatility puzzle exists because of the omitted factor aggregate volatility risk. The finding contradicts the conjecture, stocks having high idiosyncratic risk have lower returns for reasons not related to the exposition the aggregate volatility risk.

Besides, the empirical evidence contradicts the existing literature because the market should not expect any reward for holding stocks with higher idiosyncratic volatility since idiosyncratic risk is not priced, see Ross (1976). This is the reason why this problem is called idiosyncratic volatility (IVOL) puzzle. The IVOL puzzle is still an open research question because is not clear why the market needs compensation for taking a risk reducible through the diversification and moreover it is not yet evident why the market rewards this stocks with lower expected returns. Hou and Loh (2016) find that many real explanations explain less than $10 \%$ of the puzzle. Although the aggregation of the idiosyncratic shocks has no impact at aggregate level because they would average out (Lucas (1977)), recent papers questioned this claim, for example, Gabaix (2011) shows that the individual firm shocks don't average out if the distribution of firm size is fat tail; Acemoglu et al. (2012), using network analysis, find that idiosyncratic shocks may lead to aggregate fluctuations. This paper investigates if the idiosyncratic volatility puzzle can be explained by considering the linkages among assets that are formally defined by a network. The network or some measure function of it can be useful to understand if the process of idiosyncratic shocks aggregation can be seen as a risk factor, endogenously determined and helpful to explain the puzzle or at least to locate stocks subjected to it.

The network used in this paper is estimated by using by using the methododolgy of Billio et al. (2012), following the Granger causality test Granger (1969), measuring how much the series $i$ predicts the series $j$. In a bivariate framework, the Granger causality methodology can be seen as a vector autoregressive process (VAR), useful to understand as the risk can spread among the institutions. The network based on the Granger causality is not symmetric. Thus the number of links outgoing from a node (outdegree) differs from the number of connections ingoing to that node (indegree). Since the Granger causality defines a causality relation between two series, the measure indegree can collect these causality relationships for each stock. Nodes having higher indegree are shocks aggregator, in other words in network theory they are called "Authority" because they are nodes having a lot of ingoing links, see ?. The causality relation in the sense of Granger is purely an econometric test that differs from economic causality. Therefore an economic interpretation is challenging. There are two different ways to interpret the Granger causality test; the first one is related to the shocks: the causality relation in the sense of Granger

\footnotetext{
${ }^{1}$ Jackwerth and Rubinstein (1996), Bakshi et al. (2000), Chernov and Ghysels (2000), Buraschi and Jackwerth (2001), Coval and Shumway (2001),Pan (2002), Bakshi and Kapadia (2003), Eraker et al. (2003), and Carr and $\mathrm{Wu}(2008)$

${ }^{2}$ The reason why the aggregate volatility has negative market price is imputable to hedging against the downside risk, see Campbell and Hentschel (1992), French et al. (1987) and Bakshi et al. (2003).
} 
represents a proxy channel for which an idiosyncratic risk can spread to an institution to the other. For example, an exogenous shock in oil returns could affect the returns of automotive companies; a Granger causality test can detect this relation. In this framework, the indegree is the most appropriate way to catch firms more exposed to shocks of others firms. Thus, through this mechanism, an idiosyncratic shock combined with others can aggregate endogenously using the channel of the causality link, and go beyond what can be explained by an exogenous factor, to solve the idiosyncratic volatility puzzle.

The paper investigates if centrality measures associated with the Granger causality (indegree) could be seen as an exogenous factor. Since the indegree affects the aggregation of idiosyncratic shocks, the second purpose aims to examine if the factor indegree can explain the IVOL puzzle. The analysis focuses on the period chosen by Ang et al. (2006).

Another alternative point of view, beyond the causality, is related to the predictability. To say the series $\mathrm{j}$ causes in the sense of Granger the series i, it is equivalent to say that series $\mathrm{j}$ predicts the return of series $\mathrm{i}$ at time $\mathrm{t}+1$. In this work the causality inferred by Granger test is computed pairwise, filtering the common market factor. Thus stocks with higher indegree are stocks that are more predictable. The first interpretation helps to find a relationship between the indegree and the idiosyncratic volatility puzzle; the second one helps to understand why portfolios with stocks having increasing indegree have lower expected returns. This paper analyzes the relationship between expected returns and indegree based on Granger causality network for the first time. The reason for which indegree can be a factor and consequently have an impact on the expected returns is related to the nature of Granger causality: stocks having higher indegree are more predictable. To consider higher indegree stocks as more predictable because they are caused or forecasted by different series at time t- 1 , would imply that these stocks would be attractive, and the relation with the expected returns will be negative. Albeit stocks predictability represents a puzzle from market efficiency perspective, to believe according to empirical findings, that returns stocks are predictable, it means that stocks having higher indegree based on Granger causality can be expressed through other stocks which could act as benchmark behaving as another source of information for the investors and therefore reducing the disagreement as in Cujean and Hasler (2017) or Garcia (2013). Another possible explanation is that stocks with higher indegree have lower returns because they have a higher idiosyncratic risk concerning Fama and French (1993). In this way, indegree would capture the hidden factor of IVOL indirectly. Robustness checks control for this hypothesis finding that portfolios having stocks with higher indegree have lower IVOL. Given this results, if indegree depended on IVOL then portfolios sorted by indegree at previous month would have increasing returns, not reducing as observed.

The relation detected by using Granger causality may reveal the latent interactions among traders, found by Cohen-Cole et al. (2014), i.e., stocks having higher indegree can be part of the trader's strategy which has more influence among others traders. Active fund managers who build forecasting models typically use autoregressive specification. ${ }^{3}$

In this paper, I show that portfolios having stocks with higher indegree ( $3^{\text {th }}$ tercile) have lower expected return than portfolios having lower indegree ( $1^{\text {st }}$ tercile). The first contribution of the

\footnotetext{
${ }^{3}$ see Gridold and Kahn (1999) chapter 5 and Stewart et al. (2011) chapter 10
} 
paper is to show that IND, defined as difference between the ( $3^{\text {th }}$ tercile $)$ - ( $1^{\text {st }}$ tercile) portfolio monthly returns based on the indegree, is a risk factor priced, having a negative premium, when the period 1986-2000 is considered. ${ }^{4}$ The reasons are not related to the mimicking factor portfolio of the aggregate volatility changes FVIX replicated in appendix A.

If indegree is a risk factor priced like $F V I X$, then Fama and French (1993) augmented with these two factors could explain the decreasing expected returns found by Ang et al. (2006). The analysis show that the puzzle is still present.

The second contribution is to show that portfolios having higher idiosyncratic volatility stocks increase the exposition negatively to $I N D$ factor. There is a significant negative relationship between IVOL and IND.

The paper is organized as follows: Section 2 describes the current literature; section 3 defines the network estimation methodology; section 4 defines the collecting data procedure and provides some descriptive analysis; section 5 defines the indegree as a risk factor $(I N D)$ and investigates on the relation between $I N D$ and the idiosyncratic volatility risk, section 6 provides robustness checks, finally 7 concludes. Appendix A reproduces the idiosyncratic volatility puzzle and replicates the Ang et al. (2006) paper.

\section{Literature}

The literature on the role of the idiosyncratic volatility risk and expected returns is discordant. In particular Merton (1987), Ewens et al. (2013) and Malkiel and Xu (2002) suggest that the relation between the expected returns and the idiosyncratic risk should be positive because investors necessitate compensation for holding stocks not easy to diversify. The relationship between expected stock returns and idiosyncratic volatility risk is puzzling because it is not clear why investors ask less compensation for stocks having higher IVOL. Ang et al. (2006), in their seminal work observe lower expected returns for stocks with high idiosyncratic volatility concerning the Fama and French (1993) model for reasons not related to the aggregated volatility changes to which the market assigns a negative premium. The IVOL puzzle is evidence not only associated with the US market but also in G7 countries, and 23 developed markets (see Ang et al. (2009)). Stambaugh et al. (2015) impute the negative relation between the expected return and the idiosyncratic volatility risk to the arbitrage asymmetry and the arbitrage risk. Stocks with higher idiosyncratic risk deter the arbitrageurs to find stock mispriced, and consequently, stocks having more idiosyncratic risk have higher arbitrage risk. Besides, since holding an extended position is more accessible than holding a short position in the actual financial market, the negative relationship observed between expected returns and idiosyncratic volatility is imputable to these two factors. Chen and Petkova (2012) decompose the aggregate market variance in two components: average correlation and the average variance component; they find that only the latter one is priced from the market and influences stocks expected returns. High idiosyncratic volatility risk assets have lower expected returns because they offer hedging opportunity to increases in the average stocks variance.

Empirical findings extensively experience negative relation between IVOL and expected re-

\footnotetext{
${ }^{4}$ Time interval used in Ang et al. (2006)
} 
turns, ${ }^{5}$ Campbell et al. (2001) show that the increase of firm-level volatility in the period 19621997 is responsible for the market models declination and the failure of the diversification power in that period. Brandt et al. (2009) observed that the idiosyncratic volatility are higher among low-priced stocks that are held by retail investors. Baker and Wurgler (2006) define sentiment a state variable related to securities whose valuation are highly subjective, they find negative co-variation between sentiment and expected returns, in particular, high volatility stocks, have lower return only when the sentiment for that securities is high.

Herskovic et al. (2016) observe that idiosyncratic US firms volatility are synchronized and develop a theoretic model with an incomplete market of heterogeneous agents for explaining the negative relation between IVOL and expected returns. Mainly they suppose that the common idiosyncratic volatility (CIV) of the firms affects the pricing kernel of the firms through the labor market. In this paper, interconnections among assets returns are allowed to explain the IVOL puzzle; thus the aggregation mechanism is constrained to the network structure. In this direction, the way to concept the idiosyncratic shocks aggregation has changed after the global crisis in 2008 where different papers questioned Lucas (1977)' idea regarding that microeconomics shocks have no global impact. The interconnections among institutions, therefore, can vehicle idiosyncratic shocks among the financial system. For example, Acemoglu et al. (2012) used a network structure based on input-output relationships to show that aggregate fluctuations may originate from microeconomic shocks to firms. Kelly et al. (2013) developed a volatility model based on customer-supplier connectedness, in particular, they find costumers' concentration influences the volatility of their suppliers because the latter becomes less diversified. Gabaix (2011) shows that idiosyncratic firm-level shocks explain one-third of the variation in output growth. The idea is that the interconnections among assets can be used as an additional information for investigating the relationship between the idiosyncratic volatility risks and expected returns. Herskovic (2015) demonstrates that the "concentration" and the "sparsity," characteristics associated to networks, have asset pricing implications, (Ahern, 2013) finds industries that are more central in the network of intersectoral trade earn higher stock returns than industries that are less central. Buraschi and Tebaldi (2017) in their model defines two classes of equilibria. In the first class, the diversification benefits hold according to Lucas (1977), at contrary to the second case, shocks propagate endemically and persistently, and the power of diversification falls. The network topology lowers the distance between the two points of equilibrium. Since they highlight the shock causality, the network associated to these shocks is direct and thus distinguishes the "systemicness" (the contribution of each company to the aggregate network distress shock), and "vulnerability" (the exposure to aggregate network distress risk). This paper uses the same framework as Ang et al. (2006) to explain the puzzle and define the drivers influencing IVOL stocks by allowing the networks linkages among stocks. Differently from Chen and Petkova (2012), in this work, the direction is introduced on the links that can affect the aggregation of the shocks. In this case, the network used to infer the channel is based on the Granger (1969) test of the daily stocks returns applying the methodology of Billio et al. (2012). The network based on Granger Causality gives one of the most detailed stocks relationships, among all possi-

\footnotetext{
${ }^{5}$ This is true if we believe that IVOL is a good proxy of IVOL of the month. However, since IVOL is timevarying, Fu (2009) using an EGARCH as proxy of the one-month lagged idiosyncratic volatility finds a positive relationship with the expected returns.
} 
ble representations of interconnectedness,${ }^{6}$ considered the high number of assets in US market; in addition, to build a network by using a Granger causality permits to reach high frequency of links variations as in this case, at monthly level. The double interpretation of Granger test, from one hand causality and the other one predictability, can be useful to link the IVOL puzzle with the lower expected return for increasing values of indegree. Indegree, in this case, captures the "vulnerability" in the sense of Buraschi and Tebaldi (2017) i.e., stocks more exposed to shocks of other stocks (exposure to the network distress), from the other side measures most predictable stocks in the market. Cujean and Hasler (2017) in their model show that predictability rises when investors assess the uncertainty differently, especially in bad times, spreading disagreement among the investors. Stocks having indegree can be defined as most predictable stocks because they are the function of lagged stocks returns.

The first contribution of the paper is to show that indegree is a relevant state variable for explaining the cross section of stocks returns, with a negative risk premium not related to the aggregate volatility risk changes. In addition, the empirical finding show that stocks having higher indegree have on average low idiosyncratic volatility; if we consider higher indegree stocks also as a proxy of "objectivity" 7 these findings are coherent with Baker and Wurgler (2006) showing consequently that the valuation of stocks with higher indegree are more objective because the information on that stocks are superior. It worth noting that Granger causality can display latent interactions among traders' strategies. Mainly, Cohen-Cole et al. (2014) find that returns from trading are correlated with the position agents occupying a trading network; investigate how traders positions in the network influence their profitability and how shocks are transmitted across the market. Stocks having high indegree could reflect the strategy of an influencer trader. Even though the paper does not solve the puzzle, the second contribution of the paper is to show that stocks with higher IVOL have the higher negative exposition on IND. The first part of the paper focuses on the Granger causality indegree as Factor. The second part of the paper is related to show the relationship between IVOL portfolios and IND factor.

\section{Network estimation and Measures}

The procedure for the network estimation is an extension of the Granger causality method Granger (1969) proposed for the network estimation in Billio et al. (2012). An alternative approach is Diebold and Yilmaz (2014) who use the variance decompositions of VAR to build weighted directed networks, this methodology is not adopted and suited in this work because of the number extremely high of stocks, such that to estimate a VAR analysis. The series are daily stock returns with one year time horizon and one-month rolling window. Stocks returns having less of three months daily returns observations are not considered. The Granger Causality tests on a bivariate basis the following equation:

$$
R_{i t}=a_{i i} R_{i t-1}+a_{j i} R_{j t-1}+a_{M K T} M K T_{t-1}+e_{i t}
$$

\footnotetext{
${ }^{6}$ Network based on the Sales relationship is not able to cover all stocks relationships in CRSP, especially with a dynamic of one month.

${ }^{7}$ The term is opposed to "subjective" Baker and Wurgler (2006), stocks having higher indegree, being more predictable, give more information to the investors who hold that stocks. In this case, the predictability is related to the Granger causality test.
} 


$$
R_{j t}=a_{j i} R_{j t-1}+a_{i j} R_{i t-1}+a_{M K T} M K T_{t-1}+e_{j t}
$$

where $e_{i t}$ and $e_{j t}$ are the residuals of asset returns $i$ and $j$. The asset return $j$ causes in sense of Granger the asset $i$ when the coefficient $a_{j i}$ is significant, similarly the series $i$ causes in sense of Granger the asset $j$ when the coefficient $a_{i j}$ is significant. The first assumption of the equations (1) and (2) is that the residuals $e_{i t}$ and $e_{j t}$ are not correlated. In addition, the Granger causality test is augmented by the market index in order to filter the causality relations from some indirect relationship of other series through the market. The significance of the coefficient is corrected by autocorrelation and heteroskedasticity using HAC estimator from Newey and West (1987). In the bivariate model, the Granger causality test is thus a VARX if we add the Market Index. The causality presence, as detected with the above-outlined procedure, is used to determine the adjacency matrix and the associated network structure. In fact, the adjacency matrix computation is by setting $w_{i, j}=1$ when the p-value of the test on the significance of parameters $a_{i j}$ of the reference regression for asset $j$ suggests that asset $i$ Granger-cause asset $j$ at the $5 \%$ confidence level. The adjacency matrix associated with the Granger causality is not symmetric, and consequently, the graph (network) associated to the adjacency matrix is directed. A network or graph $G=(V, E)$ is a collection of vertexes $V$ and edges $E$, where the edges represent the links between the vertexes, ${ }^{8}$ with $E \subseteq(V \times V)$. Networks are represented by using the adjacency matrix $W$, a binary matrix where each element $w_{i, j}$ can take only two values, 1 and 0 . When $w_{i, j}$ is 1 , the node $j$ is linked to node $i$, with an information flow from $i$ to $j$. A value of zero identifies the absence of a link. Since the network is direct, if the series i $\rightarrow$ causes in the sense of Granger the series $\mathrm{j}$, the element $w_{i j}$ of the matrix $W$ is equal to one, and graphically we will observe a link starting from the node $i$ to the node $j$, the direction of the arrow defines the causality relationship between the two series, and consequently the matrix associated with the network is asymmetric. When the graph is directed, the number of the ingoing links differs from the number of outgoing links for each node. Assuming $\mathrm{N}$ nodes in the network, the measures associated to the ingoing links is called indegree that counts the number of links inward pointing at a node coming from its neighbors. At contrary outdegree counts the number of outgoing links starting from the nodes to its neighbors. Formally, indeegree and outdegree are defined according to the following equations:

$$
\begin{gathered}
\text { Indegree }_{i}=\sum_{i=1}^{N} W_{i j} \\
\text { Outdegree }_{i}=\sum_{j=1}^{N} W_{i j}
\end{gathered}
$$

The two measures aim to detect different kinds of effects. The first measure represents how much a node is affected by its neighbors; the second instead measures how much the node affects the neighbors. Combining indegree and outdegree through the sum and the difference is used to analyze other centrality perspectives. For example, computing the sum between indegree and outdegree as in equation (5) can be useful to group nodes more active in the networks concerning

\footnotetext{
${ }^{8}$ The terms vertex and nodes are equivalent, and both are used interchangeably in this work. In the same way, edges and links take on the same meaning.
} 
links. At the contrary, the difference between outdegree and indegree as in equation (6) captures the most unbalanced nodes: unbalanced outwardly when the measure is positive and unbalanced inwardly when it is negative. It's important to outline that the quantity of links is not relevant anymore for this centrality measure.

$$
\begin{aligned}
& \text { Outdegree }_{i}+\text { Indegree }_{i}=\sum_{j=1}^{N} W_{i j}+\sum_{i=1}^{N} W_{i j} \\
& \text { Outdegree }_{i}-\text { Indegree }_{i}=\sum_{j=1}^{N} W_{i j}-\sum_{i=1}^{N} W_{i j}
\end{aligned}
$$

Another centrality measure is the eigenvector centrality. Introduced by Bonacich (1987), which captures the node prestige as a function of the neighbors' prestige. Formally it is the eigenvector associated to the highest eigenvalue of the adjacency matrix. Defined with $x_{i}$ the score of node $\mathrm{i}, \lambda_{1}$ the maximum eigenvalue associated to the adjacency matrix $\mathrm{W}$, the eigenvector centrality is defined as equation (7)

$$
x_{i}=\frac{1}{\lambda_{1}} \sum_{j=1}^{N} W_{i j} x_{j}
$$

Since with the Granger causality, the adjacency matrix is not symmetric, the left eigenvector differs from the right eigenvector. This work focuses on the effect coming from the system on the node, for this reason the eigenvector considered is exclusively the left one.

To detect the network sparsity is useful to define another centrality measure, the ratio between the actual number of links among the nodes over the all possible ones: the density, defined by this equation:

$$
D=\sum_{i=1}^{N} \sum_{j=1}^{N} W_{i j} /(N(N-1))
$$

The density is always greater than zero and lower than 1 . Higher density indicates networks full of interconnections, density close to zero indicates that the links among nodes are rare and the network is sparse.

\section{Data}

The time interval considered in this analysis is from January 1986 to December $2000 .^{9}$ This section reports the cleaning procedure adopted for the stocks returns available in CRSP. ${ }^{10}$

Figure (1) shows the monthly variation of the number of firms by looking at the steps during the clearing procedure.

The cleaning procedure can be summarized with the following method. The initial database is reduced by considering all the firms listed on AMEX, NYSE, NASDAQ. Once merged CRSP by Compustat, all the stocks having missing book value are deleted from that month. ${ }^{11}$ The number

\footnotetext{
${ }^{9}$ As in Ang et al. (2006)

${ }^{10}$ https : //wrds-web. wharton. upenn.edu/wrds/query_forms/navigation. cfm?navId=128

${ }^{11}$ Stocks having positive and negative book values are considered. The number of stocks having negative book
} 
of firms even reduces considerably when the firms having missing book value are excluded. The pattern of sawtooth shape suggests a seasonality at the end of the year. The average number of firms across the whole sample is 4902 . The total number keep reducing when we hold only the ordinary stocks and the stocks having daily observations for that month greater than 17 .

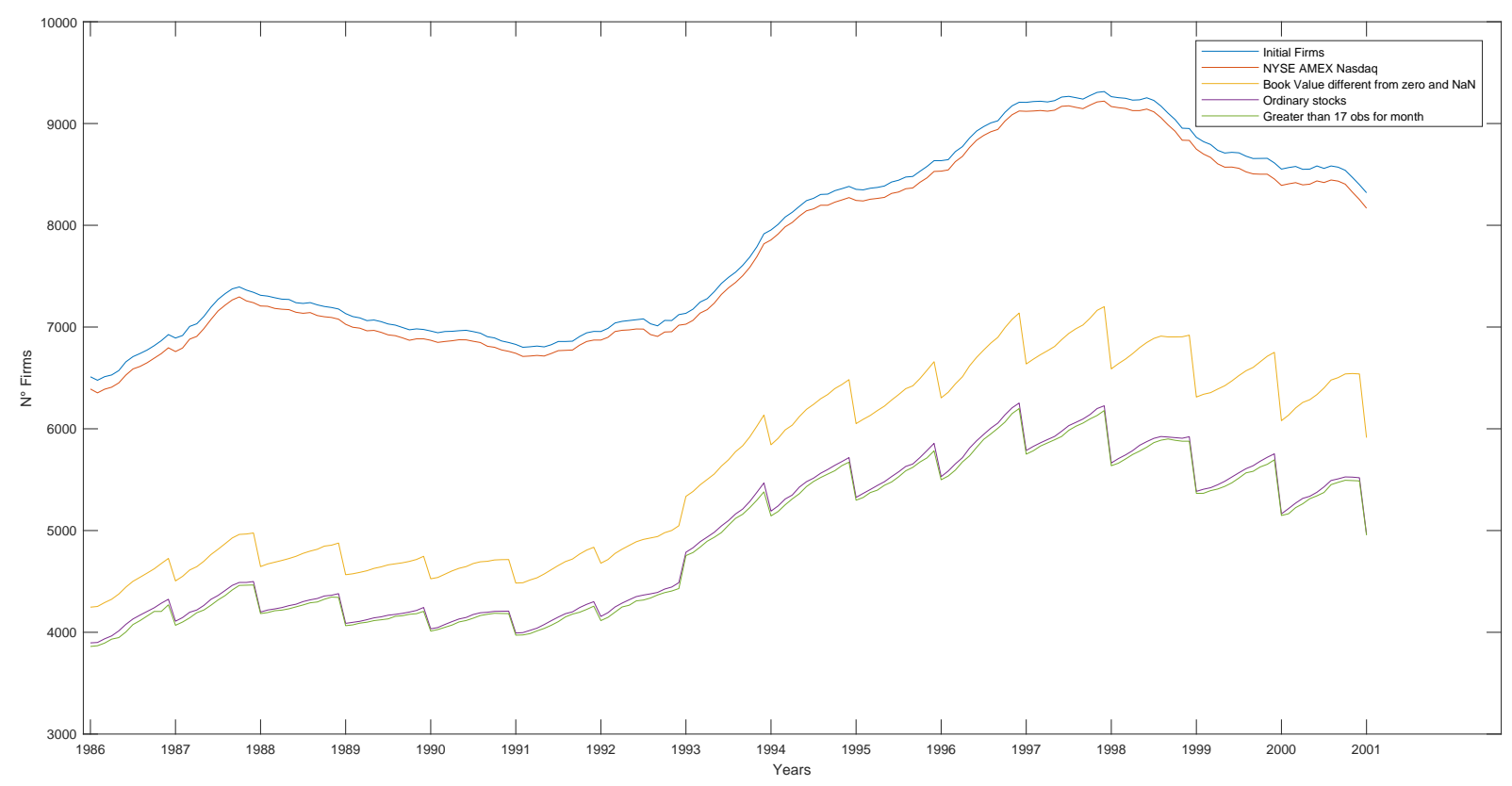

Figure 1: Number of firms across time. The figure exhibits the number firms monthly variations from January 1986 to December 2000. Each line represents a step in the cleaning procedure.

CRSP provides the average between the bid and ask price when the stock price information is missing. ${ }^{12}$ The stock market capitalization is computed as the product between the price and the outstanding share.

Figure (2) indicates the centrality measures computed monthly by using the network estimated with the Granger Causality. The density is reported on the left axes. The density defines the network connectivity that has a positive trend starting from a value of $3 \%$ at the beginning of the period to $7 \%$ at the end of 2000. The right axis of the figure exhibits the average and the standard deviation of indegree. The average indegree according to the density, reveals an increasing pattern with a hump in the year 1999, where it reaches the global maximum of the sample, 440 links of average. The standard deviation has an increasing pattern positive and moderate which can manifest a disequilibrium and asymmetries in term of ingoing connections, and consequently to influence the way of shocks aggregations.

value is hugely lower than stocks having positive book value.

${ }^{12}$ These observations in CRSP have denoted by a negative sign, and they are considered in the current analysis. 


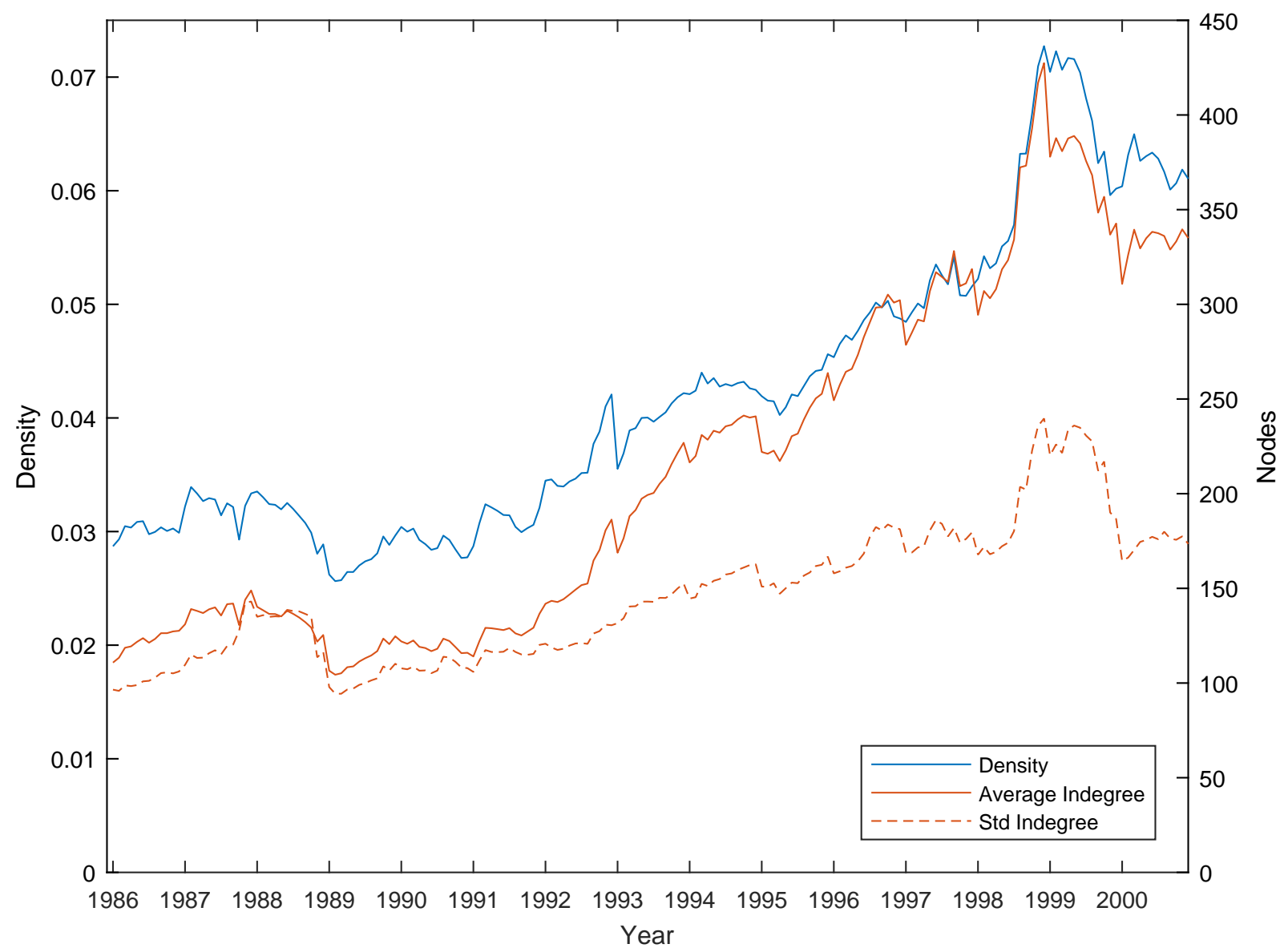

Figure 2: Centrality measures of networks based on Granger causality. The density (on the left axis), the average and the standard deviations of indegree (on the right axis) relative network estimated with the Granger causality by month, from January 1986 to December 2000.

Table (1) summarizes 25 portfolios statistics sorted by size and book-to-market value weighted. The $M E$ indicates market capitalization and $B M$ is the book-to-market ratio. As highlighted by Fama and French (1993) the expected returns are positively correlated with the market capitalization and the book-to-market ratio. The standard deviation of the monthly portfolios returns decreases by increasing the book-to-market exposure. The skewness of the returns distributions is close to zero or slightly negative, instead, the kurtosis is high. The 25 portfolios return distributions are leptokurtic. Table (2) reports the statistics for 48 industry portfolios. The returns are monthly and value-weighted; the stocks aggregation is according to SIC (Standard Industrial Classification). Financial, Pharmaceutical Products and Electronic Equipment have higher monthly returns in average respectively 1.75\%, 1.79\%, and 1.86\%; Precious Metals have the higher standard deviations. Returns have negative skewness, and positive kurtosis ${ }^{13}$ as for the 25 portfolios sorted by size and book-to-market. I used these two different kinds of portfolios returns to understand if indegree can explain the returns variations in cross section.

\footnotetext{
${ }^{13}$ It is necessary to subtract the number 3 to compare the portfolios returns kurtosis with the normal distribution case
} 
Table 1: Descriptive analysis 25 Portfolios sorted by Size and Book-to-Market The tables reports the statistics of portfolios monthly returns value weighted from January 1986 to December 2000 .

\begin{tabular}{|c|c|c|c|c|c|c|}
\hline \multicolumn{7}{|c|}{ Descriptive analysis 25 Portfolios sorted by Size and Book-to-Market } \\
\hline Portfolio & Mean & $\begin{array}{l}\text { Standard } \\
\text { Deviation }\end{array}$ & Min & Max & Kurtosis & Skewness \\
\hline ME1 BM1 & 0.49 & 8.48 & -34.23 & 38.94 & 7.70 & 0.20 \\
\hline ME1 BM2 & 1.26 & 7.43 & -30.94 & 40.94 & 9.83 & 0.40 \\
\hline ME1 BM3 & 1.22 & 5.68 & -28.70 & 22.06 & 8.34 & -0.70 \\
\hline ME1 BM4 & 1.47 & 5.46 & -28.88 & 25.45 & 10.33 & -0.64 \\
\hline ME1 BM5 & 1.39 & 5.27 & -28.88 & 16.46 & 9.26 & -1.19 \\
\hline ME2 BM1 & 0.90 & 7.47 & -32.71 & 28.18 & 5.90 & -0.53 \\
\hline ME2 BM2 & 1.18 & 5.84 & -31.67 & 17.62 & 8.36 & -1.18 \\
\hline ME2 BM3 & 1.21 & 4.81 & -28.13 & 12.62 & 10.79 & -1.72 \\
\hline ME2 BM4 & 1.33 & 4.56 & -25.44 & 10.37 & 9.76 & -1.64 \\
\hline ME2 BM5 & 1.36 & 5.29 & -28.84 & 14.55 & 8.57 & -1.32 \\
\hline ME3 BM1 & 1.09 & 7.08 & -29.79 & 24.61 & 5.40 & -0.61 \\
\hline ME3 BM2 & 1.28 & 5.45 & -29.05 & 13.49 & 8.83 & -1.26 \\
\hline ME3 BM3 & 1.13 & 4.53 & -24.29 & 11.16 & 8.61 & -1.36 \\
\hline ME3 BM4 & 1.33 & 4.41 & -23.03 & 13.43 & 8.49 & -1.31 \\
\hline ME3 BM5 & 1.50 & 4.77 & -26.17 & 11.92 & 9.16 & -1.42 \\
\hline ME4 BM1 & 1.40 & 6.33 & -25.94 & 26.22 & 6.23 & -0.29 \\
\hline ME4 BM2 & 1.29 & 4.95 & -28.83 & 12.97 & 10.80 & -1.49 \\
\hline ME4 BM3 & 1.24 & 4.76 & -25.00 & 14.07 & 8.31 & -1.20 \\
\hline ME4 BM4 & 1.40 & 4.12 & -18.26 & 11.94 & 5.70 & -0.71 \\
\hline ME4 BM5 & 1.42 & 4.84 & -23.84 & 15.96 & 6.84 & -0.90 \\
\hline ME5 BM1 & 1.49 & 4.96 & -21.64 & 15.36 & 5.26 & -0.67 \\
\hline ME5 BM2 & 1.36 & 4.77 & -22.42 & 16.53 & 6.66 & -0.81 \\
\hline ME5 BM3 & 1.28 & 4.61 & -21.71 & 11.34 & 6.50 & -1.08 \\
\hline ME5 BM4 & 1.24 & 4.51 & -15.17 & 16.09 & 4.37 & -0.53 \\
\hline ME5 BM5 & 1.52 & 5.02 & -18.73 & 15.65 & 4.63 & -0.51 \\
\hline
\end{tabular}


Table 2: Descriptive analysis 48 Industry Portfolios The tables reports the statistics of portfolios monthly returns value weighted from January 1986 to December 2000.

\begin{tabular}{|c|c|c|c|c|c|c|}
\hline \multicolumn{7}{|c|}{ Descriptive analysis 48 Industry Portfolios } \\
\hline Portfolio & Mean & $\begin{array}{l}\text { Standard } \\
\text { Deviation }\end{array}$ & Min & Max & Kurtosis & Skewness \\
\hline Agric & 0.95 & 6.26 & -28.79 & 28.88 & 6.99 & -0.16 \\
\hline Food & 1.39 & 5.35 & -17.88 & 19.59 & 4.36 & 0.06 \\
\hline Soda & 1.27 & 7.66 & -25.94 & 38.27 & 6.31 & 0.41 \\
\hline Beer & 1.79 & 6.13 & -19.76 & 22.02 & 4.48 & -0.15 \\
\hline Smoke & 1.59 & 7.45 & -24.93 & 22.80 & 4.07 & -0.20 \\
\hline Toys & 0.91 & 7.05 & -34.41 & 20.09 & 5.98 & -0.70 \\
\hline Fun & 1.39 & 6.68 & -31.86 & 19.26 & 6.59 & -0.95 \\
\hline Books & 1.26 & 5.34 & -22.57 & 14.67 & 4.67 & -0.31 \\
\hline Hshld & 1.22 & 5.15 & -21.64 & 18.54 & 5.45 & -0.62 \\
\hline Clths & 1.06 & 7.06 & -30.90 & 25.06 & 5.66 & -0.52 \\
\hline Hlth & 1.00 & 7.43 & -31.43 & 21.13 & 5.01 & -0.64 \\
\hline MedEq & 1.47 & 5.59 & -20.56 & 16.33 & 4.07 & -0.42 \\
\hline Drugs & 1.79 & 5.57 & -19.11 & 16.27 & 3.82 & -0.29 \\
\hline Chems & 1.16 & 5.55 & -28.00 & 22.05 & 7.27 & -0.48 \\
\hline Rubbr & 1.25 & 6.00 & -30.57 & 19.27 & 7.35 & -0.85 \\
\hline Txtls & 0.87 & 6.41 & -32.51 & 23.11 & 6.93 & -0.80 \\
\hline BldMt & 1.16 & 5.88 & -27.74 & 18.25 & 6.41 & -0.71 \\
\hline Cnstr & 1.08 & 6.64 & -31.10 & 20.03 & 5.98 & -0.52 \\
\hline Steel & 1.14 & 7.05 & -30.48 & 30.67 & 6.84 & 0.01 \\
\hline FabPr & 0.82 & 6.53 & -26.67 & 25.96 & 5.62 & -0.29 \\
\hline Mach & 1.18 & 6.07 & -31.19 & 16.08 & 7.20 & -1.03 \\
\hline ElcEq & 1.71 & 6.37 & -32.20 & 18.28 & 6.80 & -0.67 \\
\hline Autos & 1.16 & 6.56 & -28.33 & 19.33 & 5.08 & -0.63 \\
\hline Aero & 1.27 & 5.98 & -30.23 & 14.99 & 7.24 & -1.05 \\
\hline Ships & 0.41 & 6.97 & -32.27 & 17.17 & 5.26 & -0.47 \\
\hline Guns & 0.96 & 6.58 & -30.08 & 18.86 & 6.85 & -1.01 \\
\hline Gold & 0.33 & 11.52 & -30.93 & 78.68 & 13.83 & 1.66 \\
\hline Mines & 1.04 & 6.47 & -33.32 & 20.50 & 7.11 & -0.51 \\
\hline Coal & 1.35 & 9.57 & -30.11 & 44.04 & 6.70 & 0.78 \\
\hline Oil & 1.20 & 4.94 & -18.21 & 16.75 & 4.64 & 0.23 \\
\hline Util & 1.04 & 3.93 & -10.77 & 11.72 & 3.00 & -0.13 \\
\hline Telcm & 1.38 & 5.03 & -15.58 & 14.35 & 3.90 & -0.54 \\
\hline PerSv & 0.72 & 6.37 & -28.25 & 24.47 & 5.83 & -0.43 \\
\hline BusSv & 1.73 & 7.02 & -27.54 & 24.08 & 4.85 & -0.38 \\
\hline Comps & 1.44 & 7.77 & -24.37 & 23.10 & 3.70 & -0.03 \\
\hline Chips & 1.86 & 7.95 & -27.82 & 27.27 & 4.85 & -0.51 \\
\hline LabEq & 1.40 & 6.90 & -30.15 & 22.04 & 5.59 & -0.21 \\
\hline Paper & 1.14 & 5.67 & -26.35 & 24.27 & 7.44 & -0.03 \\
\hline Boxes & 0.98 & 6.52 & -28.24 & 20.05 & 5.58 & -0.62 \\
\hline Trans & 1.08 & 5.53 & -27.90 & 14.20 & 6.70 & -0.95 \\
\hline Whlsl & 1.05 & 5.03 & -28.64 & 12.64 & 9.49 & -1.33 \\
\hline Rtail & 1.46 & 6.01 & -29.17 & 14.36 & 5.87 & -0.77 \\
\hline Meals & 1.05 & 5.56 & -24.04 & 15.98 & 5.04 & -0.58 \\
\hline Banks & 1.55 & 6.22 & -24.19 & 16.14 & 4.73 & -0.68 \\
\hline Insur & 1.35 & 5.47 & -16.85 & 22.87 & 4.74 & -0.25 \\
\hline RlEst & 0.03 & 5.58 & -22.68 & 14.20 & 4.51 & -0.70 \\
\hline Fin & 1.75 & 6.49 & -25.91 & 18.45 & 5.48 & -0.67 \\
\hline Other & 0.84 & 7.15 & -26.37 & 20.15 & 4.41 & -0.43 \\
\hline
\end{tabular}




\section{$5 \quad$ Network as Exogenous Factor}

This section investigates whether the indegree of the network based on the Granger causality test is a risk factor priced. Granger causality methodology is used in this work because is a compromise between estimation accuracy and computational time. In this work, the first assumption related the Granger causality is to neglect all the effects coming from the other series that are instead present in VARX, because of the number of stocks extremely high. For this reason, I discard the variance decomposition proposed by Diebold and Yilmaz (2014). By using the pairwise Granger causality test, there is an overestimation link that increases the density of the networks. On the other hand, to use VARX constrained to LASSO would underestimate the connections across the stocks returns.

There are different centrality measures defined for various applications. It is worth to notice that indegree is the only centrality measure able to capture the mechanism of idiosyncratic shocks aggregation. At the contrary, outdegree, since it measures the number of outgoing links, reveals the spreading mechanism of idiosyncratic shocks from a node to the system. The sum and the difference between outdegree and indegree as in equation (5) and (6) used in Billio et al. (2012) would make difficult to distinguish if the market cared more to indegree or outdegree. Finally, the eigenvector centrality would capture higher order aggregation mechanism of the idiosyncratic shocks, but as outlined by Buraschi and Tebaldi (2017) it is not useful for the directed network. Although this analysis focuses on indegree, I tested all the other measures as robustness check in table (13) in section 6 .

The preliminary analysis is to sort the stocks in three quantiles concerning the indegree and to compute the portfolios returns at time $t+1$. The table (3) shows that the value-weighted average of the portfolios returns decreases as soon as the tercile portfolios have stocks with higher indegree. The market share, the size and the book to market ratio is roughly constant across the portfolios quintiles. Finally, the CAPM and Fama and French (1993) (3FF) model alphas are inversely proportional to the indegree loading, and they are statistically significant only in the last tercile (3). There is a difference in $-0.33 \%$ per month between the average of the highest tercile having higher indegree and the lowest one, this difference is not statistically significant when whole period is considered. Figure (3) shows the cumulative quantile portfolio returns having stocks with increasing indegree computed at the previous month $t-1$, particular portfolios with higher indegree have lower returns, especially in the second part of the period starting from 1991, the small and medium indegree portfolios outperform the more top indegree portfolios. The medium and lower indegree performances are so similar because the network is sparse especially in the first part of the sample with a density of $3 \%$ thus the smallest and the medium quantile are close to zero. In the second part of the sample, the density doubles to $7 \%$ as reported in figure (2) left axes. On the right axis, the table indicates the mean and the standard deviation of the indegree. As observed for the density, the average and the standard deviation inflate in the second half of the time horizon, the higher variance of indegree allows to distinguish the middle from the lowest quantile. In this works, although the difference is not so vast, the proposed risk factor based on the indegree of Granger causality test is the difference between the $3^{\text {th }}-1^{\text {st }}$ hereafter IND. 
Table 3: Portfolios sorted by indegree based on Granger Causality network. The statistics are relative to the quantile portfolios ordered for the indegree computed by using equation (3). The value-weighted average and the standard deviation are relative to the returns monthly based. Market share defines the market capitalization of the portfolio; the logarithm of stock market capitalization represents the Size, and B/M is the Book-to-Market ratio average. Alpha columns represent the intercept by regressing the portfolio returns with the CAPM and the Fama and French (1993) model. The time interval is from January 1986 to December 2000 as Ang et al. (2006). Robust Newey and West (1987) t-statistics are reported in square brackets.

\section{Portofolios Sorted by Indegree}

$\begin{array}{cccccccc}\text { Rank } & \text { Mean } & \text { Std Dev. } & \begin{array}{c}\text { Market } \\ \text { Share }\end{array} & \text { Size } & \text { B/M } & \begin{array}{c}\text { CAPM } \\ \text { Alpha }\end{array} & \begin{array}{c}\text { FF-3 } \\ \text { Alpha }\end{array} \\ \mathbf{1} & 1.51 & 5.29 & 32.19 \% & 6.99 & 0.44 & 0.06 & 0.14 \\ & & & & & & {[0.61]} & {[1.59]} \\ \mathbf{2} & 1.45 & 4.60 & 38.18 \% & 7.22 & 0.45 & 0.05 & 0.02 \\ & & & & & & {[0.7]} & {[0.34]} \\ \mathbf{3} & 1.18 & 4.32 & 29.64 \% & 6.91 & 0.49 & -0.15 & -0.22 \\ & & & & & & {[-1.34]} & {[-2.16]} \\ \mathbf{3 - 1} & -0.33 & & & & -0.21 & -0.36 \\ & {[1.62]} & & & & & {[-1.05]} & {[-2.07]}\end{array}$

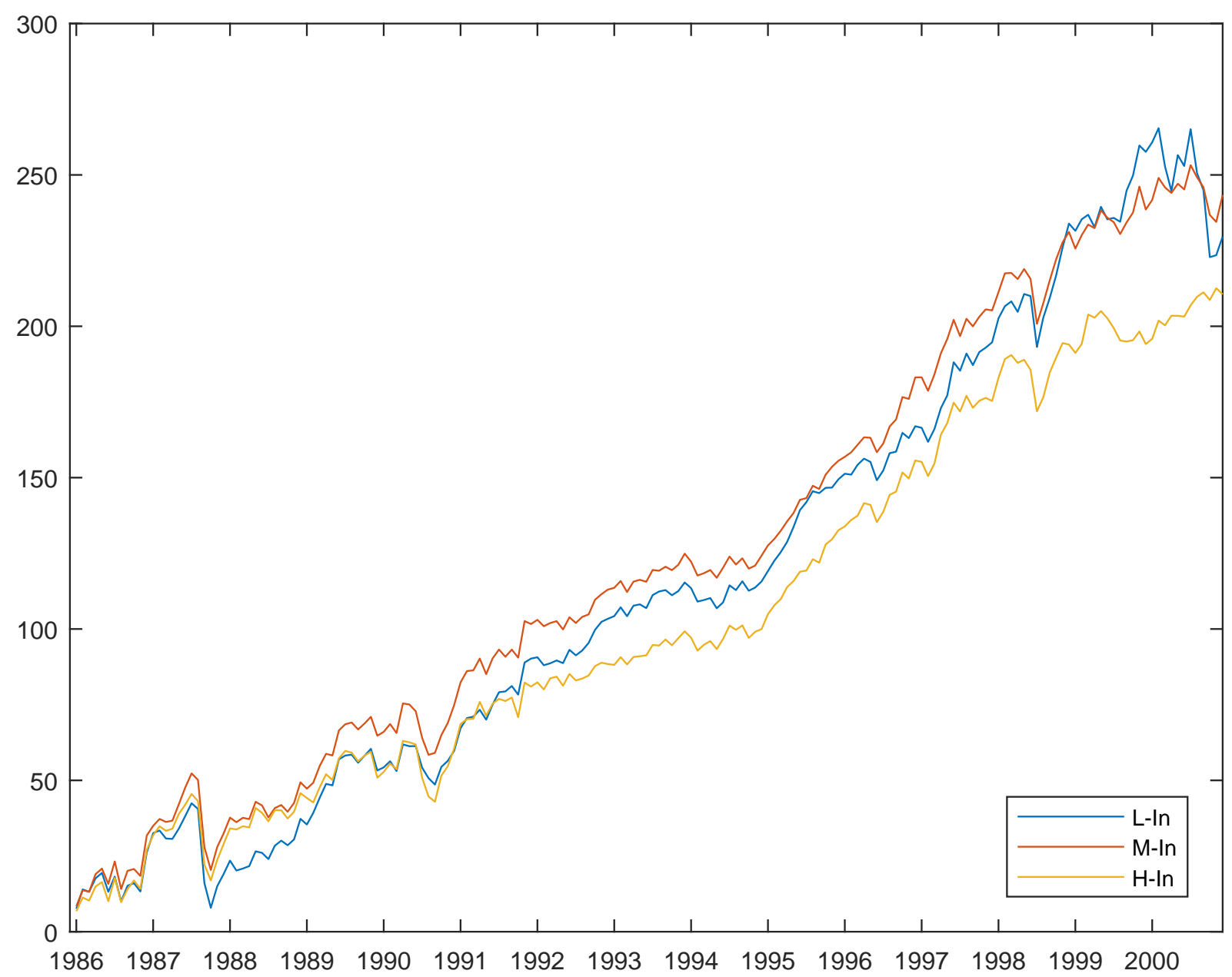

Figure 3: Cumulative Returns Indegree based on the Granger causality. Cumulative Returns of the portfolio quantile by picking the stocks having high Indegree for the network estimated with the Granger causality 


\subsection{Factors descriptive analysis}

The table (4) displays the statistical analysis of the factors monthly based, from January 1986 to December 2000. The factors considered are respectively the risk free (RF), the extra market return (MKT), Small Minus Big size firms (SMB), High Minus Low growth (HML), Momentum (UMD), ${ }^{14}$ Liquidity level (LIQ), liquidity Innovations (LIQ_INN) and liquidity value weighted (LIQVW) are respecitively aggregate liquidity level factor, innovations and traded liquidity factor value weighted see Pástor and Stambaugh (2003). ${ }^{15}$ Aggregate volatility delta change $(\Delta V I X)$ and mimicking tracking portfolio on the aggregate volatility risk (FVIX) risk factors. The statistics show that except for the risk-free asset return all the other distributions behave as not normal distributions and have leptokurtic shapes. The $M K T$ and $L I Q$ have a negative skew, $H M L, U M D$ and FVIX have roughly a distribution symmetric, while the other risk factors have a positive skewness. The risk-free asset has on average a monthly return of $0.4 \%$ with a standard deviation of $0.1 \%$. The $M K T$ has a positive monthly extra return with an average of $0.8 \%$ with the standard deviation of $4.5 \%$ instead the momentum has an average monthly return of 1

Table 4: Risk factor descriptive analysis. The table shows the statistics of the most common factors in the literature as well as indegree $I N D$ based on the Granger causality network. $M K T$, $H M L, S M B$ and $U M D$ are Fama and French (1993) and Carhart (1997) momentum factors; $L I Q, L I Q \_I N N, L I Q V W$ are respectively aggregate liquidity level, innovations and traded liquidity value weighted factors, see Pástor and Stambaugh (2003). Finally, $\Delta V I X$ and FVIX represent the aggregate volatility innovations and its mimicking tracking portfolio. Monthly observations from January 1986 December 2000.

\begin{tabular}{ccccccc}
\hline \multicolumn{7}{c}{ Descriptive Analysis } \\
\hline $\begin{array}{c}\text { Risk } \\
\text { Factor }\end{array}$ & Mean & $\begin{array}{c}\text { Standard } \\
\text { Deviation }\end{array}$ & Min & Max & Kurtosis & Skewness \\
\hline RF & 0.441 & 0.122 & 0.210 & 0.790 & 2.916 & 0.338 \\
IND & -0.332 & 2.713 & -11.894 & 19.632 & 14.088 & 1.697 \\
MKT & 0.844 & 4.523 & -23.240 & 12.470 & 7.389 & -1.204 \\
SMB & -0.216 & 3.692 & -17.170 & 22.080 & 12.382 & 1.025 \\
HML & 0.259 & 3.083 & -10.490 & 11.290 & 4.900 & 0.089 \\
UMD & 1.003 & 3.752 & -9.080 & 18.380 & 7.076 & 0.628 \\
LIQ & -0.019 & 0.066 & -0.461 & 0.201 & 14.792 & -2.217 \\
LIQ_INN & 0.002 & 0.065 & -0.384 & 0.287 & 12.830 & -1.564 \\
LIQVW & 0.000 & 0.035 & -0.091 & 0.110 & 3.556 & 0.328 \\
FVIX & -0.818 & 2.787 & -7.961 & 14.785 & 7.972 & 1.224 \\
$\Delta$ VIX & 0.059 & 4.855 & -15.380 & 39.030 & 27.294 & 3.113
\end{tabular}

Table (5) shows the factors correlation. Particularly it shows $I N D$ respectively correlated

\footnotetext{
${ }^{14} R F M K T, H M L, S M B$ and $U M D$ are available in http://mba.tuck.dartmouth.edu/pages/faculty/ken. french/data_library.html

${ }^{15} L I Q, \quad L I Q \_I N N$ and $L I Q V W$ are available in https://wrds-web.wharton.upenn.edu/wrds/ds/ famafrench/liq_ps. cfm?navId=204
} 
negatively with $M K T$ at -0.21 , with $S M B-0.21$ and with the Momentum $U M D$ at -0.6 and positively correlated with $\triangle V I X$ aggregate volatility risk changes and its mimicking portfolio $F V I X$. The correlations with $I N D$ have magnitudes lower than 0.5 , except the correlation with $U M D$. If we take in account the other factors, $M K T$ is moderately correlated with $S M B, U M D$ respectively at 0.13 and 0,21 ; strongly negatively correlated with $F V I X-0.99$; and sufficiently with $\Delta V I X-0.56$. The correlation between FVIX and $\Delta V I X$ is 0.56 .

Table 5: Risk factor correlations. Correlations table among risk factors. IND is the difference between the $3^{\text {th }} 1^{\text {st }}$ tercile as in table (3). $M K T, H M L, S M B$ and $U M D$ are Fama and French (1993) and Carhart (1997) risk factors; $L I Q, L I Q-I N N, L I Q V W$ are respectively aggregate liquidity level, innovations and traded liquidity value weighted factors, see Pástor and Stambaugh (2003). Finally, $\Delta V I X$ and FVIX represent the aggregate volatility innovations and its mimicking tracking portfolio. Monthly observations from January 1986 December 2000.

\begin{tabular}{|c|c|c|c|c|c|c|c|c|c|c|}
\hline \multicolumn{11}{|c|}{ Correlation } \\
\hline & IND & MKT & SMB & HML & UMD & LIQ & LIQ_INN & LIQVW & FVIX & $\Delta$ VIX \\
\hline IND & 1.000 & -0.209 & -0.212 & 0.457 & -0.613 & 0.017 & 0.060 & -0.102 & 0.213 & 0.105 \\
\hline MKT & -0.209 & 1.000 & 0.137 & -0.434 & 0.212 & 0.254 & 0.300 & -0.107 & -0.992 & -0.559 \\
\hline SMB & -0.212 & 0.137 & 1.000 & -0.508 & 0.307 & 0.044 & -0.009 & -0.210 & -0.152 & -0.163 \\
\hline HML & 0.457 & -0.434 & -0.508 & 1.000 & -0.485 & -0.016 & 0.015 & 0.101 & 0.454 & 0.169 \\
\hline UMD & -0.613 & 0.212 & 0.307 & -0.485 & 1.000 & 0.005 & -0.059 & -0.025 & -0.206 & -0.088 \\
\hline LIQ & 0.017 & 0.254 & 0.044 & -0.016 & 0.005 & 1.000 & 0.874 & 0.051 & -0.261 & -0.353 \\
\hline LIQ_INN & 0.060 & 0.300 & -0.009 & 0.015 & -0.059 & 0.874 & 1.000 & 0.050 & -0.305 & -0.348 \\
\hline LIQVW & -0.102 & -0.107 & -0.210 & 0.101 & -0.025 & 0.051 & 0.050 & 1.000 & 0.111 & 0.062 \\
\hline FVIX & 0.213 & -0.992 & -0.152 & 0.454 & -0.206 & -0.261 & -0.305 & 0.111 & 1.000 & 0.561 \\
\hline$\Delta$ VIX & 0.105 & -0.559 & -0.163 & 0.169 & -0.088 & -0.353 & -0.348 & 0.062 & 0.561 & 1.000 \\
\hline
\end{tabular}

\subsection{Missing Factor on 25 Size-BM portfolios}

This section tests the marginal contribution of $I N D$ on top of the standard Fama and French (1993) multifactor model. The dependent variables of equation (9) are the monthly extra returns of the 25 size and book-to-market portfolios. ${ }^{16}$ The abnormal returns are defined as the difference $Z_{t}$ between $Y_{t}-\hat{Y}_{t}$, where $\hat{Y}_{t}$ is the forecast of $Y_{t}$ as in equation (10).

$$
\begin{gathered}
Y_{t}=\alpha+\beta_{M K T} M K T_{t}+\beta_{H M L} H M L_{t}+\beta_{S M L} S M L_{t}+\epsilon_{t} \\
\hat{Y}_{t}=\hat{\beta}_{M K T} M K T_{t}+\hat{\beta}_{H M L} H M L_{t}+\hat{\beta}_{S M B} S M B_{t}
\end{gathered}
$$

Regressing the abnormal returns at monthly level with IND establishes whether the proposed factor contributes to explain the abnormal returns by looking at the significance of the factor loading. To make the analysis more robust, IND is tested separately but also compared and jointly tested with other two factors: the momentum $U M D$ and the mimicking portfolios on the aggregate volatility changes FVIX. The choice of these factors is related to two different reasons: In the first case, $U M D$ and $I N D$ have a correlation equal to -0.6 . Therefore it is

\footnotetext{
${ }^{16}$ Datadownloadedfromhttp://mba.tuck.dartmouth.edu/pages/faculty/ken.french/data_library.html
} 
necessary to prevent that $I N D$ explains the abnormal returns because of the interaction with $U M D$. In the second case, although the correlation with $F V I X$ is equal to $0.21, F V I X$ can be useful to investigate if $I N D$ has a different component concerning the aggregate volatility. Thus, $Z_{t}$ is regressed respectively with the $I N D$ risk factor, with the mimicking factor portfolio on $\Delta V I X, F V I X$, and together as from equation (11) to equation (13).

$$
\begin{gathered}
Z_{t}=a+b_{I N D} I N D_{t}+\eta_{t} \\
Z_{t}=a+b_{F V I X} F V I X_{t}+\eta_{t} \\
Z_{t}=a+b_{I N D} I N D_{t}+b_{F V I X} F V I X_{t}+\eta_{t}
\end{gathered}
$$

Table (6) panel A shows the indegree factor loading as in equation (11); on the right the tstatistic with Newey and West (1987) corrected standard errors in the square brackets. The betas are mostly significant, they don't increase their loading with respect to the size or bookto-market dimension. The Panel A shows that the indegree $I N D$ can be considered as relevant variable with 17 over 25 beta significant. Panel B reports instead the beta and the t-statistic as in equation (12), highlighting that only few $\beta_{F V I X}$ are significant reflecting only a marginal role of this risk factor with respect the 25 size book-to-market portfolios. Finally, Panel C reports the results when both factors are in the same regression as in equation (13), the results show clearly that IND still remains significant while the t-statistics on $\beta_{F V I X}$ are higher than Panel B.

$$
\begin{gathered}
Z_{t}=a+b_{U M D} U M D_{t}+\eta_{t} \\
Z_{t}=a+b_{I N D} I N D_{t}+b_{U M D} U M D_{t}+\eta_{t}
\end{gathered}
$$

Table (7) panel A shows same results of (6) panel A, since they refer to the same equation (11). Panel B reports instead the beta and the t-statistic as in equation (14), highlighting that the number of factor loading significant $\beta_{U M D}$ is only six over 25 portfolios. Finally, panel C reports the results when both factor are in the same regression as in equation (15), the number of factor loading significant reduces, from 17 to 11 for $\beta_{I N D}$ and from 6 to 4 for $\beta_{U M D}$. However it is possible to claim that the impact of $I N D$ is relavant and evident even though the interaction with the momentum reduces the global significance slightly below the half of the number of the portfolios. 


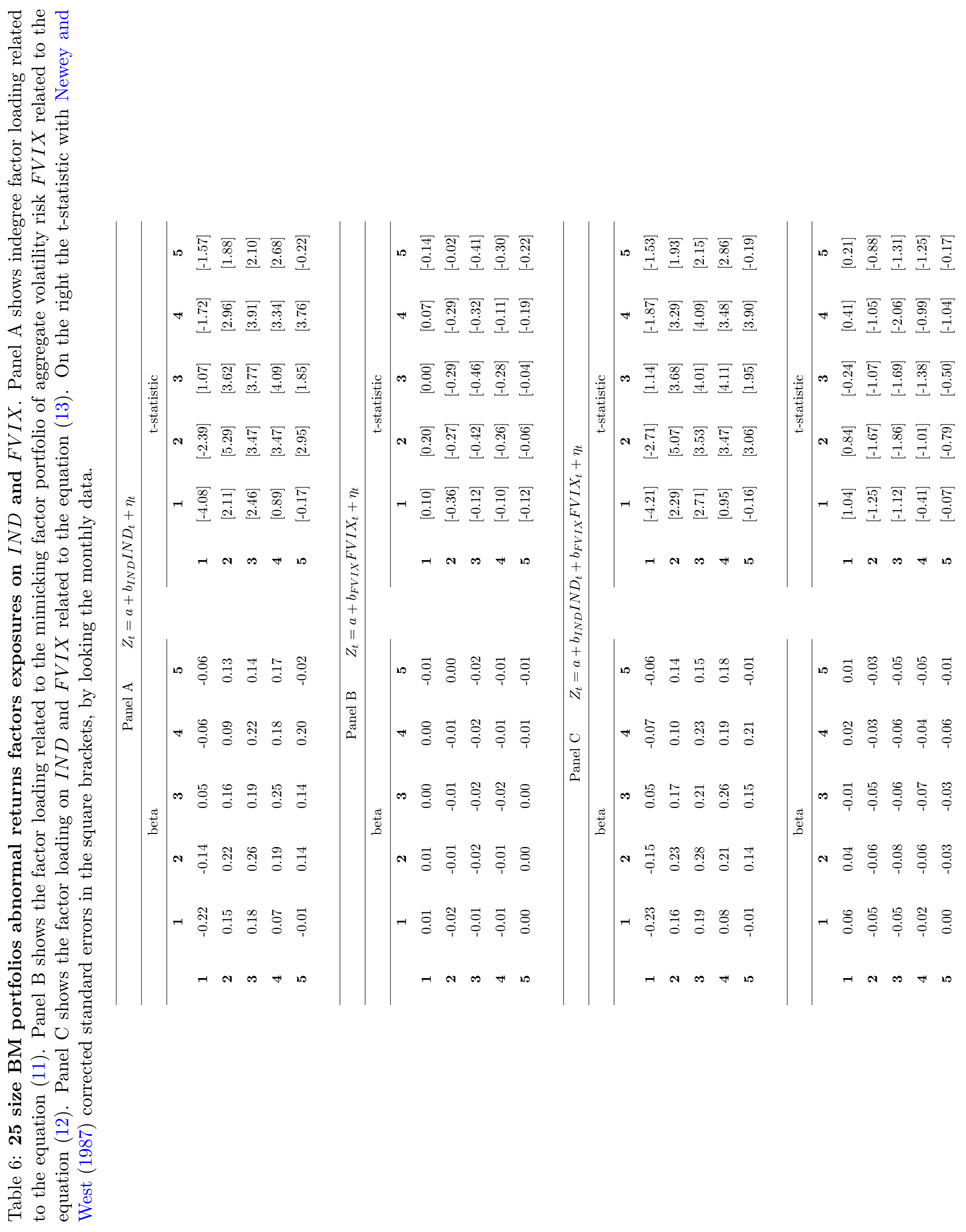




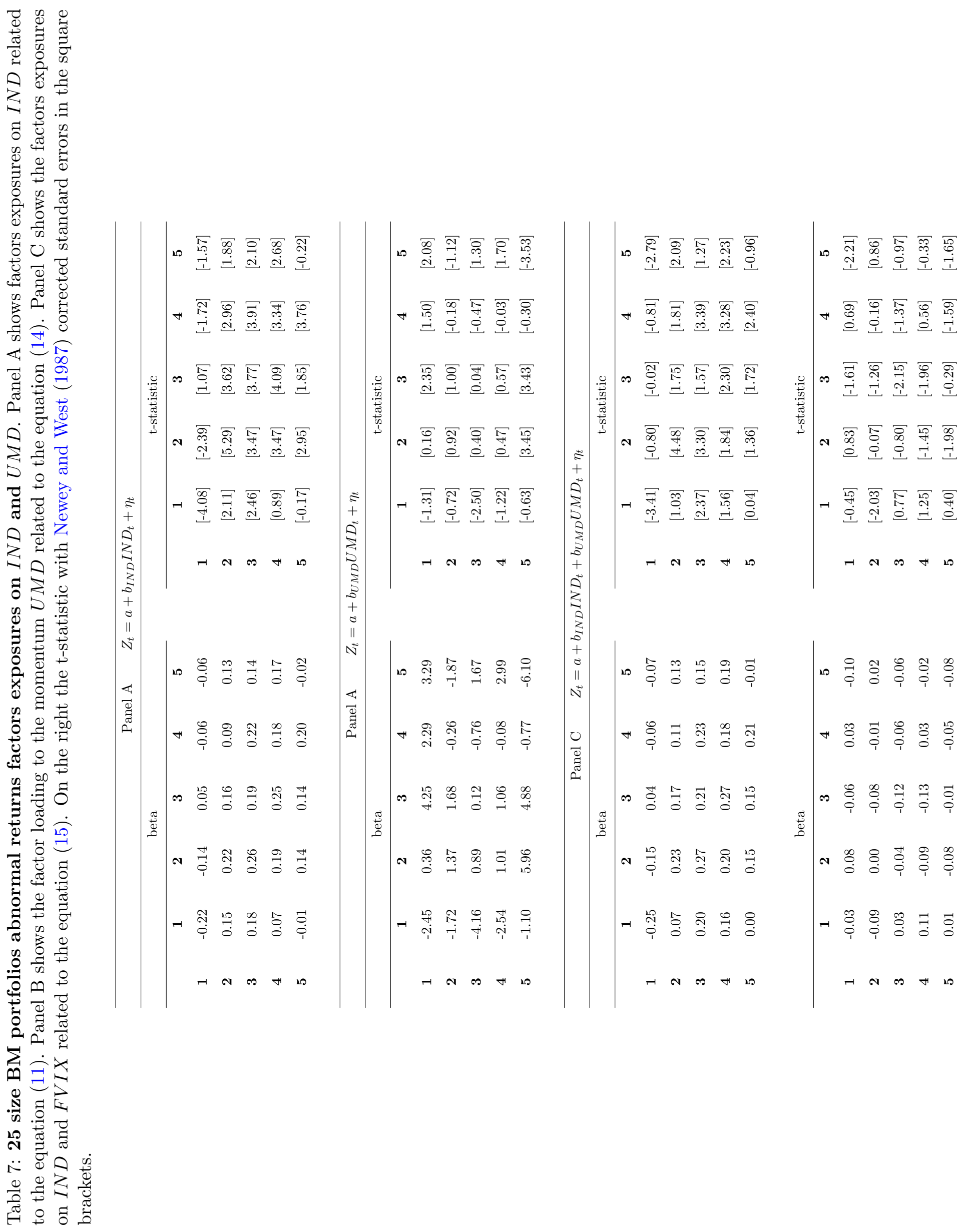




\subsection{Risk Premium}

This section proposes to compute the price of the $I N D$ risk factor, by applying the Fama and MacBeth (1973) procedure. The expected returns are related to the market price of risk according to the equation (16). The equation puts in relation the expected returns of the assets or portfolios i, with the risk-free, the market price of the risk factors $\lambda$ and the factor loading on that asset. The equation is in cross-section.

$$
E\left[R_{i}\right]=r f+\beta \Lambda+\eta
$$

Fama and MacBeth (1973) propose a procedure in two stages able to estimate the market price of risk, where the factor loading is the OLS time series estimates from January 1986 to December 2000. The second stage regression instead is an OLS regression where the covariates are the betas estimates in the first stage. The market price of risk for $I N D$ risk factor is computed by using both 25 size book-to-market portfolios and 48 industry portfolios. The procedure is applied to Fama and French (1993) factors model and successively stepwise augmented by Indegree IND, mimicking factor portfolio of aggregate volatility Index change FVIX, the Momentum factor of Carhart (1997) UMD and Liquidity Innovations factors LIQ_INN Pástor and Stambaugh (2003). Shanken (1992) procedure corrects the results.

Table (8) reports the premiums estimates by looking at the 25 size book-to-market portfolios. The left part of the table exhibits the results when the second stage regression considers the intercept for computing the premium coefficients, while on the right part, the intercept is removed and the results are corrected for Shanken (1992). The outcomes differ depending on whether the intercept is omitted or not: the model with intercept indicates that only the $S M B$ and $U M D$ are significant; the model without intercept determines the significance of $M K T$, $F V I X$, and $U M D$. The first model shows an adjusted $R^{2}$ higher than the model without the intercept, besides in the VI, VII, and VIII the adjusted $R^{2}$ is negative, suggesting that the intercept offers better performance results in term of adjusted $R^{2}$.

Table (9) reports the premium coefficients for the 48 Industry portfolios. In this case, the model with intercept without Shanken (1992) correction on the left part produces similar results if compared to the model without intercept. The $M K T, H M L, I N D, F V I X$ are significant in both cases. $S M B$ and $U M D$ lose the significance after the Shanken (1992) corrections. Finally, the adjusted $R^{2}$ increases roughly by $4 \%$ when we add the $I N D$ risk factor.Fama and MacBeth (1973) procedure produces higher adjusted $R^{2}$ for 48 Industry portfolios rather than for 25 portfolios sorted by size and book-to-Market. Although risk factor $I N D$ is significant only in case of 48 industry portfolios, in both circumstances is always negative. If the market decides to price $I N D$ negatively, means that $I N D$ stands for insurance for investors, i.e., offers good outcomes in the bad states and bad outcomes in good ones. The $I N D$ risk premium is equal to $-0.5 \%$. The coefficient significant does not nullify the significance of FVIX showing that the $I N D$ is priced for reasons not related to the mimicking factor portfolio of the aggregate volatility change innovations. A possible explanation, assuming IND as the risk factor with a negative price of risk could be that stocks having higher indegree are the more predictable. Further developments in this paper will consider wider time intervals with a focus on the financial crisis. 
Table 8: Fama-MacBeth (1973) factor premiums $25 \mathrm{~B} / \mathrm{M}$ portfolios. The table shows the premium computed on the 25 portfolios sorted by size and book-to-market portfolios using Fama and MacBeth (1973) procedure. The Fama and French (1993) model is the benchmark in the first column and stepwise augmented by $I N D, F V I X, U M D$ and $L I Q_{-} I N N$. The left part and the right part of the table report the premium estimates with and without intercept. The results are corrected by Shanken (1992). The square brackets present t-statistic with Newey and West (1987) corrected standard errors.

\begin{tabular}{|c|c|c|c|c|c|c|c|c|c|c|}
\hline & I & II & III & IV & $\mathrm{V}$ & VI & VII & VIII & IX & $\mathrm{X}$ \\
\hline \multirow[t]{2}{*}{ Constant } & 1.74 & 1.61 & 1.55 & 1.41 & 1.26 & - & - & - & - & - \\
\hline & {$[2.97]$} & {$[2.56]$} & {$[2.2]$} & {$[2.32]$} & {$[1.95]$} & - & - & - & - & - \\
\hline \multirow[t]{2}{*}{ MKT } & -0.79 & -0.63 & -0.57 & -0.44 & -0.30 & 0.86 & 0.94 & 0.97 & 0.96 & 0.95 \\
\hline & {$[-1.41]$} & {$[-1.02]$} & {$[-0.81]$} & {$[-0.73]$} & {$[-0.46]$} & {$[2.54]$} & {$[2.75]$} & {$[2.83]$} & {$[2.78]$} & {$[2.75]$} \\
\hline \multirow[t]{2}{*}{ SMB } & -0.19 & -0.21 & -0.21 & -0.22 & -0.22 & -0.11 & -0.17 & -0.18 & -0.19 & -0.20 \\
\hline & {$[-2.44]$} & {$[-2.46]$} & {$[-2.4]$} & {$[-2.89]$} & {$[-2.84]$} & {$[-0.4]$} & {$[-0.61]$} & {$[-0.64]$} & {$[-0.67]$} & {$[-0.67]$} \\
\hline \multirow[t]{2}{*}{ HML } & 0.04 & 0.05 & 0.05 & 0.14 & 0.13 & 0.04 & 0.06 & 0.08 & 0.17 & 0.14 \\
\hline & {$[0.46]$} & {$[0.56]$} & {$[0.57]$} & {$[1.57]$} & {$[1.42]$} & {$[0.16]$} & {$[0.27]$} & {$[0.36]$} & {$[0.72]$} & {$[0.61]$} \\
\hline \multirow[t]{2}{*}{ IND } & & -0.17 & -0.13 & -0.16 & -0.25 & & -0.43 & -0.13 & -0.17 & -0.34 \\
\hline & & {$[-0.55]$} & {$[-0.33]$} & {$[-0.48]$} & {$[-0.7]$} & & {$[-1.49]$} & {$[-0.38]$} & {$[-0.43]$} & {$[-0.81]$} \\
\hline \multirow[t]{2}{*}{ FVIX } & & & 0.38 & 0.14 & 0.01 & & & -0.45 & -0.62 & -0.72 \\
\hline & & & {$[0.96]$} & {$[0.42]$} & {$[0.02]$} & & & {$[-2.02]$} & {$[-2.64]$} & {$[-2.89]$} \\
\hline \multirow[t]{2}{*}{ UMD } & & & & 1.85 & 2.14 & & & & 2.11 & 2.60 \\
\hline & & & & {$[2.83]$} & {$[2.76]$} & & & & {$[3.21]$} & {$[3.08]$} \\
\hline \multirow[t]{2}{*}{ LIQ_INN } & & & & & 0.01 & & & & & 0.03 \\
\hline & & & & & {$[0.78]$} & & & & & {$[1.57]$} \\
\hline$R^{\wedge} 2$ & $25.89 \%$ & $27.29 \%$ & $27.42 \%$ & $49.72 \%$ & $51.21 \%$ & $-5.21 \%$ & $3.49 \%$ & $8.96 \%$ & $34.71 \%$ & $40.28 \%$ \\
\hline $\operatorname{Adj} R^{\wedge} 2$ & $15.31 \%$ & $12.74 \%$ & $8.32 \%$ & $32.97 \%$ & $31.12 \%$ & $-14.77 \%$ & $-10.29 \%$ & $-9.25 \%$ & $17.53 \%$ & $20.38 \%$ \\
\hline $\begin{array}{c}\text { Shanken } \\
\text { Correction }\end{array}$ & $\mathrm{N}$ & $\mathrm{N}$ & $\mathrm{N}$ & $\mathrm{N}$ & $\mathrm{N}$ & $\mathrm{Y}$ & $\mathrm{Y}$ & $\mathrm{Y}$ & $\mathrm{Y}$ & $\mathrm{Y}$ \\
\hline
\end{tabular}


Table 9: Fama-MacBeth (1973) factor premiums 48 Industry portfolios. The table shows the premium computed on the 48 Industry portfolios using Fama and MacBeth (1973) procedure. The Fama and French (1993) model is the benchmark in the first column and stepwise augmented by $I N D, F V I X, U M D$ and $L I Q \_I N N$. The left part and the right part of the table report the premium estimates with and without intercept. The results are corrected by Shanken (1992). The square brackets present t-statistic with Newey and West (1987) corrected standard errors.

\begin{tabular}{|c|c|c|c|c|c|c|c|c|c|c|}
\hline & I & II & III & IV & $\mathrm{V}$ & VI & VII & VIII & IX & $\mathrm{X}$ \\
\hline \multirow[t]{2}{*}{ Constant } & 0.20 & 0.29 & 0.06 & 0.08 & 0.10 & - & - & - & - & - \\
\hline & {$[0.75]$} & {$[1.13]$} & {$[0.2]$} & {$[0.29]$} & {$[0.35]$} & - & - & - & - & - \\
\hline \multirow[t]{2}{*}{ MKT } & 0.74 & 0.72 & 0.97 & 0.98 & 0.96 & 0.93 & 0.99 & 1.03 & 1.06 & 1.06 \\
\hline & [2.94] & {$[3]$} & [3.34] & {$[3.43]$} & {$[3.32]$} & {$[2.71]$} & {$[2.86]$} & {$[2.97]$} & {$[3.05]$} & {$[3.05]$} \\
\hline \multirow[t]{2}{*}{ SMB } & -0.38 & -0.45 & -0.42 & -0.36 & -0.35 & -0.39 & -0.46 & -0.42 & -0.36 & -0.35 \\
\hline & {$[-2.36]$} & {$[-2.91]$} & {$[-2.74]$} & {$[-2.32]$} & {$[-2.25]$} & {$[-1.11]$} & {$[-1.34]$} & {$[-1.18]$} & {$[-1.05]$} & {$[-1.03]$} \\
\hline \multirow[t]{2}{*}{ HML } & -0.67 & -0.54 & -0.58 & -0.53 & -0.54 & -0.68 & -0.57 & -0.58 & -0.54 & -0.55 \\
\hline & {$[-5.83]$} & {$[-4.41]$} & {$[-4.68]$} & {$[-4.3]$} & {$[-4.31]$} & {$[-2.71]$} & {$[-2.25]$} & {$[-2.3]$} & {$[-2.1]$} & {$[-2.13]$} \\
\hline \multirow[t]{2}{*}{ IND } & & -0.59 & -0.58 & -0.55 & -0.57 & & -0.58 & -0.57 & -0.55 & -0.57 \\
\hline & & {$[-4.35]$} & {$[-4.28]$} & {$[-4.18]$} & {$[-4.19]$} & & {$[-2.09]$} & {$[-2.06]$} & {$[-1.97]$} & {$[-1.99]$} \\
\hline \multirow[t]{2}{*}{ FVIX } & & & -0.55 & -0.57 & -0.55 & & & -0.59 & -0.61 & -0.61 \\
\hline & & & {$[-3.44]$} & {$[-3.59]$} & {$[-3.47]$} & & & {$[-2.71]$} & {$[-2.77]$} & {$[-2.77]$} \\
\hline \multirow[t]{2}{*}{ UMD } & & & & 1.05 & 1.07 & & & & 1.05 & 1.07 \\
\hline & & & & {$[3.53]$} & {$[3.56]$} & & & & {$[1.96]$} & [1.95] \\
\hline \multirow[t]{2}{*}{ LIQ_INN } & & & & & 0.01 & & & & & 0.01 \\
\hline & & & & & {$[0.86]$} & & & & & {$[0.53]$} \\
\hline$R^{\wedge} 2$ & $53.14 \%$ & $58.13 \%$ & $60.23 \%$ & $62.84 \%$ & $63.26 \%$ & $52.53 \%$ & $56.88 \%$ & $60.19 \%$ & $62.77 \%$ & $63.15 \%$ \\
\hline $\operatorname{Adj} R^{\wedge} 2$ & $49.94 \%$ & $54.23 \%$ & $55.50 \%$ & $57.41 \%$ & $56.83 \%$ & $50.42 \%$ & $53.94 \%$ & $56.49 \%$ & $58.34 \%$ & $57.75 \%$ \\
\hline $\begin{array}{l}\text { Shanken } \\
\text { Correction }\end{array}$ & $\mathrm{N}$ & $\mathrm{N}$ & $\mathrm{N}$ & $\mathrm{N}$ & $\mathrm{N}$ & $\mathrm{Y}$ & $\mathrm{Y}$ & $\mathrm{Y}$ & $\mathrm{Y}$ & $\mathrm{Y}$ \\
\hline
\end{tabular}

\subsection{Relationship with the Idiosyncratic volatility puzzle}

Empirical evidence suggests that the $I N D$ can be considered as a risk factor priced by the market.This part of the analysis investigates if $I N D$ can explain the idiosyncratic volatility puzzle, and secondly which is the relation in term of factor exposure $\beta_{I N D}$ between portfolios sorted by IVOL and the risk factor IND. Table (10) displays the value weighted average of portfolios returns ordered by IVOL with respect to a Fama and French (1993) model as in equation (21) from January 1986 to December 2000. The last three colums report the alpha and factors exposures of $I N D$ and FVIX of the equations (17).

$$
r_{i t}=\alpha_{i}+\beta_{M K T} M K T_{t}+\beta_{S M B} S M B_{t}+\beta_{H M L} H M L_{t}+\beta_{I N D} I N D_{t}+\beta_{F V I X} F V I X_{t}+\epsilon_{t}
$$

Particularly, table (10) shows that the proposed factor $I N D$ is not able to explain the puzzle because the alpha coefficients are still statistically significant. The results are invariant with the removal of FVIX from the equation (17). The results are more interesting if we observe how much change the exposition on $I N D$ as soon as the portfolios have an increasing IVOL, factor loading on $I N D \beta_{I N D}$ decreases significantly for all portfolios. To deepen this behavior table (11) shows the factor exposure on indegree based on equation (17) of the 25 portfolios sorted by Indegree based on the Granger causality and IVOL. By construction, portfolios having stocks with higher indegree have a factor loading $\beta_{I N D}$ on $I N D$ increasing. When the quintile portfolios are controlled for indegree, then the factor loading on the Indegree decreases, and it is almost 
cases significant.

Table 10: Portfolios sorted by idiosyncratic volatility. Quantile portfolios ordered with respect to the IVOL of equation (21). The statistics Mean and Standard Deviation are relative to the total portofolio returns monthly percentage. The Alpha columns report the Jensens' alpha with respect to the CAPM and the Fama and French (1993). The columns $\beta_{I N D}$ and $\beta_{F V I X}$ represent the exposure $I N D$ and $F V I X$ by using the full sample regression of equation (17). Robust Newey and West (1987) t-statistics are reported in square brackets. The sample period is from January 1986 to December 2000.

\begin{tabular}{|c|c|c|c|c|c|c|}
\hline \multicolumn{7}{|c|}{ Portofolios Sorted by Idiosyncratic Volatility } \\
\hline Rank & Mean & Std Dev. & $\begin{array}{c}\text { Market } \\
\text { Share }\end{array}$ & Alpha & $\beta_{I N D}$ & $\beta_{F V I X}$ \\
\hline \multirow[t]{2}{*}{1} & 1.40 & 4.16 & $61.42 \%$ & 0.07 & 0.16 & -0.10 \\
\hline & & & & {$[0.7]$} & {$[3.29]$} & {$[-0.43]$} \\
\hline \multirow[t]{2}{*}{2} & 1.33 & 4.83 & $24.45 \%$ & -0.46 & 0.09 & -1.55 \\
\hline & & & & {$[-3.59]$} & {$[2.13]$} & {$[-5.98]$} \\
\hline \multirow[t]{2}{*}{3} & 1.31 & 6.21 & $8.96 \%$ & -0.65 & -0.13 & -2.07 \\
\hline & & & & {$[-3.37]$} & {$[-2.26]$} & {$[-4.46]$} \\
\hline \multirow[t]{2}{*}{4} & 0.72 & 7.74 & $3.81 \%$ & -0.88 & -0.26 & -1.16 \\
\hline & & & & {$[-3.52]$} & {$[-4.3]$} & {$[-2.46]$} \\
\hline \multirow[t]{2}{*}{5} & -0.24 & 9.17 & $1.36 \%$ & -1.59 & -0.52 & -0.49 \\
\hline & & & & {$[-4.31]$} & {$[-4.72]$} & {$[-0.6]$} \\
\hline \multirow[t]{2}{*}{$5-1$} & -1.47 & & & -1.65 & -0.67 & -0.39 \\
\hline & {$[-2.37]$} & & & {$[-3.96]$} & {$[-5.63]$} & {$[-0.42]$} \\
\hline
\end{tabular}

Table 11: Factor loading of 25 portfolios sorted by indegree and IVOL on IND risk factor. The table displays the beta's on $I N D$ by considering the 25 portfolios returns sorted by Indegree and IVOL.

\begin{tabular}{cccccc}
\hline \multicolumn{7}{c}{25 portfolios sorted by Indegree and IVOL: $\beta_{I N D}$} \\
\hline Rank & $\mathbf{1}$ & $\mathbf{2}$ & $\mathbf{3}$ & $\mathbf{4}$ & $\mathbf{5}$ \\
$\mathbf{1}$ & -0.34 & -0.48 & -0.46 & -0.58 & -0.73 \\
& {$[-3.04]$} & {$[-5.31]$} & {$[-3.46]$} & {$[-5.16]$} & {$[-4.02]$} \\
$\mathbf{2}$ & -0.22 & -0.16 & -0.35 & -0.40 & -0.30 \\
& {$[-3.37]$} & {$[-1.29]$} & {$[-2.92]$} & {$[-2.18]$} & {$[-2.59]$} \\
$\mathbf{3}$ & 0.23 & 0.16 & 0.28 & -0.02 & -0.07 \\
& {$[4.55]$} & {$[2.31]$} & {$[3.07]$} & {$[-0.13]$} & {$[-0.71]$} \\
$\mathbf{4}$ & 0.41 & 0.36 & 0.21 & 0.27 & -0.16 \\
& {$[9.45]$} & {$[4.76]$} & {$[2.1]$} & {$[2.36]$} & {$[-1.22]$} \\
$\mathbf{5}$ & 0.55 & 0.63 & 0.62 & 0.46 & 0.20 \\
& {$[11.27]$} & {$[7.91]$} & {$[7.26]$} & {$[3.1]$} & {$[1.43]$}
\end{tabular}




\section{Robustness check}

\subsection{Contemporaneous IVOL of Portfolios sorted by Indegree}

This section investigates if the decreasing expected returns of portfolios having increasing indegree are linked to the fact that these portfolios have higher IVOL. If this Hypothesis were accepted, it would mean that IVOL would be hidden factor behind the negative relationship between indegree and expected returns. this section, therefore, analyzes if the observed effect of decreasing expected returns with respect to increasing indegree is defined "by construction" or could be related to economic reasons. The procedure is the following: for each month the contemporaneous IVOL in equation (9) is computed for all stocks contained in tercile portfolios. Statistics are computed monthly and then averaged across the whole sample.

Table (12) highlights that stocks contained in portfolios having lower indegree have in average higher IVOL mean, IVOL median and value-weighted average. It means that if indegree were priced for reasons related to IVOL, then the expected returns would have increasing values for higher indegree. Also, empirical findings show as market share drives idiosyncratic volatility concerning Fama and French (1993), as observed in table (10) because portfolios having higher IVOL are driven by small size firms stocks. At the contrary, this is not the case for portfolios sorted by indegree because their market share composition is constant roughly at $30 \%$ across the terciles. Therefore the negative relationship between IVOL and the factor loading on IND $\beta_{I N D}$ is not imputable to the size of firms.

Table 12: Descriptive Analysis of contemporaneous IVOL for stocks belonging to tercile portfolios sorted by indegree. For each IVOL statistics computed for each stocks daily return with respect to the Fama and French (1993) model, the results are averaged across whole sample.

\begin{tabular}{ccccccc}
\hline \multicolumn{6}{c}{ Statistics of Idiosyncractic Volatility for portfolio sorted by Indegree } \\
\hline \multirow{2}{*}{ Rank } & Mean & Median & $\begin{array}{c}\text { Standard } \\
\text { Deviation }\end{array}$ & $\begin{array}{c}\text { Value } \\
\text { Weighted } \\
\text { Average }\end{array}$ & Min & Max \\
& & & 72.33 & 6.13 & -0.90 & 1821.39 \\
$\mathbf{1}$ & 18.61 & 2.86 & 34.99 & 4.58 & -0.86 & 769.04 \\
$\mathbf{2}$ & 12.24 & 2.06 & 29.93 & 4.71 & -0.82 & 615.30 \\
$\mathbf{3}$ & 11.65 & 2.01 & & & &
\end{tabular}

\subsection{Expected returns and centrality measures}

The last part of robustness checks tests the relationship between other centrality measures and stocks expected returns. In other words, portoflios returns are computed by sorting stocks according the centrality measures described in section 3. Table (13) displays the results. Particularly, panel A exhibits the value weighted returns at time $t+1$ for portfolios terciles sorted by outdegree at time $t$ according the equation (4), averaged across the sample. Surprisingly, the difference between the $3^{\text {th }}-1^{\text {st }}$ is not significant and close to zero. On the contrary of indegree case in table (3), market share is higher for portfolio having lower outdegree. The last columns of the table shows alphas coefficient with respect to the CAPM and the Fama and French (1993), they are not significant. 
Panel B reports the results by sorting the terciles portfolios by the sum of outdegree plus indegree as in equation (5). The variable takes into account of stock more active is a sense of links (ingoing and outgoing), the direction loses its role. As table (3), portfolios having stocks with higher indegree+outdegree have lower expected returns, the magnitude is low and not significant. In addition, portfolios having lower outdegree plus indegree have higher market capitalization, however, the alpha relative of the third tercile for Fama and French (1993) is the only one significant.

Panel $\mathrm{C}$ reports terciles value-weighted portfolios returns averaged across all sample, computed by sorting the difference between the outdegree and indegree as in equation (6). The measure considers the net effect of spreading and absorbing the shocks. In this case, portfolios having an increasing difference between outdegree and indegree have higher returns. The difference between the $3^{\text {th }}-1^{\text {st }}$ is not significant and equal to $0.15 \%$. The alphas with respect the CAPM and Fama and French (1993) are not significant and very low.

Panel D reports terciles value-weighted portfolios returns, averaged across the sample, computed by sorting the eigenvector centrality as in equation (7). The measure considers the indirect effect is coming from the neighbors. As table (3) portfolios having eigenvector centrality have lower expected returns, as indegree, because the left eigenvector captures the impact coming from the system. The difference between the $3^{\text {th }}-1^{\text {st }}$ is not significant and equal to $-0.12 \%$. The alphas with respect the CAPM and Fama and French (1993) are not significant and very low. The results shown in table (13) indicate clearly that the centrality measures previously described have a weaker effect on expected returns than indegree. In addition, alphas t-statistic with respect to CAPM and Fama and French (1993) model suggest that these measures are not good candidates as missing factors of stocks returns. 
Table 13: Portfolios sorted by centrality measures based on Granger causality network, robusteness checks. The statistics are relative to the quantile portfolios ordered with respect to outdegree in Panel A equation (4), with respect to outdegree plus indegree in Panel $\mathrm{B}$, with respect to Outdegree minus indegree in Panel $\mathrm{C}$, with respect to eigenvector centrality in Panel D. The value weighted average and the standard deviation are relative to the returns monthly based. Market share defines the market capitalization of the portfolio, Size is computed as logarithm of stock market capitalization and B/M is the Book-to-Market ratio average. Alpha columns represent the intercept by regressing the porfolio returns with the CAPM and the Fama and French (1993) model. The time interval is from January 1986 to December 2000 as Ang et al. (2006). Robust Newey and West (1987) t-statistics are reported in square brackets.

\begin{tabular}{|c|c|c|c|c|c|c|c|}
\hline \multicolumn{8}{|c|}{ Panel A: Portofolios Sorted by Outdegree } \\
\hline Rank & Mean & Std Dev. & $\begin{array}{c}\text { Market } \\
\text { Share }\end{array}$ & Size & $\mathrm{B} / \mathrm{M}$ & $\begin{array}{c}\text { CAPM } \\
\text { Alpha }\end{array}$ & $\begin{array}{l}\text { FF-3 } \\
\text { Alpha }\end{array}$ \\
\hline \multirow[t]{2}{*}{1} & 1.40 & 4.40 & $46.67 \%$ & 7.40 & 0.44 & 0.04 & 0.05 \\
\hline & & & & & & {$[0.44]$} & {$[0.8]$} \\
\hline \multirow[t]{2}{*}{2} & 1.47 & 4.80 & $26.76 \%$ & 6.87 & 0.48 & 0.01 & 0.03 \\
\hline & & & & & & {$[0.18]$} & {$[0.37]$} \\
\hline \multirow[t]{2}{*}{3} & 1.39 & 4.92 & $26.58 \%$ & 6.83 & 0.47 & -0.06 & -0.08 \\
\hline & & & & & & {$[-0.58]$} & {$[-0.87]$} \\
\hline \multirow[t]{2}{*}{$3-1$} & -0.01 & & & & & -0.10 & -0.13 \\
\hline & {$[-0.04]$} & & & & & {$[-0.55]$} & {$[-0.92]$} \\
\hline \multicolumn{8}{|c|}{ Panel B: Portofolios Sorted by Outdegree+Indegree } \\
\hline Rank & Mean & Std Dev. & $\begin{array}{c}\text { Market } \\
\text { Share }\end{array}$ & Size & $\mathrm{B} / \mathrm{M}$ & $\begin{array}{c}\text { CAPM } \\
\text { Alpha }\end{array}$ & $\begin{array}{l}\text { FF-3 } \\
\text { Alpha }\end{array}$ \\
\hline \multirow[t]{2}{*}{1} & 1.41 & 4.59 & $45.25 \%$ & 7.38 & 0.43 & 0.02 & 0.06 \\
\hline & & & & & & {$[0.17]$} & {$[0.71]$} \\
\hline \multirow[t]{2}{*}{2} & 1.56 & 4.56 & $28.30 \%$ & 6.92 & 0.46 & 0.16 & 0.15 \\
\hline & & & & & & {$[1.77]$} & {$[1.77]$} \\
\hline \multirow[t]{2}{*}{3} & 1.22 & 4.91 & $26.45 \%$ & 6.83 & 0.48 & -0.22 & -0.27 \\
\hline & & & & & & {$[-1.71]$} & {$[-2.28]$} \\
\hline \multirow[t]{2}{*}{$3-1$} & -0.19 & & & & & -0.24 & -0.33 \\
\hline & {$[-0.9]$} & & & & & {$[-1.08]$} & {$[-1.82]$} \\
\hline \multicolumn{8}{|c|}{ Panel C: Portofolios Sorted by Outdegree-Indegree } \\
\hline Rank & Mean & Std Dev. & $\begin{array}{c}\text { Market } \\
\text { Share }\end{array}$ & Size & $\mathrm{B} / \mathrm{M}$ & $\begin{array}{l}\text { CAPM } \\
\text { Alpha }\end{array}$ & $\begin{array}{l}\text { FF-3 } \\
\text { Alpha }\end{array}$ \\
\hline \multirow[t]{2}{*}{1} & 1.40 & 4.27 & $42.73 \%$ & 7.29 & 0.45 & 0.06 & 0.04 \\
\hline & & & & & & {$[0.93]$} & {$[0.79]$} \\
\hline \multirow[t]{2}{*}{2} & 1.35 & 4.70 & $31.07 \%$ & 7.01 & 0.46 & -0.08 & -0.05 \\
\hline & & & & & & {$[-1.02]$} & {$[-0.69]$} \\
\hline \multirow[t]{2}{*}{3} & 1.55 & 5.03 & $26.21 \%$ & 6.80 & 0.46 & 0.06 & 0.07 \\
\hline & & & & & & {$[0.63]$} & {$[0.8]$} \\
\hline \multirow[t]{2}{*}{$3-1$} & 0.15 & & & & & 0.00 & 0.03 \\
\hline & {$[0.87]$} & & & & & {$[0.02]$} & {$[0.22]$} \\
\hline \multicolumn{8}{|c|}{ Panel D: Portofolios Sorted by Eigenvector Centrality } \\
\hline Rank & Mean & Std Dev. & $\begin{array}{c}\text { Market } \\
\text { Share }\end{array}$ & Size & $\mathrm{B} / \mathrm{M}$ & $\begin{array}{c}\text { CAPM } \\
\text { Alpha }\end{array}$ & $\begin{array}{l}\text { FF-3 } \\
\text { Alpha }\end{array}$ \\
\hline \multirow[t]{2}{*}{1} & 1.44 & 4.63 & $36.85 \%$ & 7.11 & 0.46 & 0.05 & 0.07 \\
\hline & & & & & & {$[0.46]$} & {$[0.71]$} \\
\hline \multirow[t]{2}{*}{2} & 1.48 & 4.80 & $25.85 \%$ & 6.83 & 0.48 & 0.02 & 0.04 \\
\hline & & & & & & {$[0.28]$} & {$[0.45]$} \\
\hline \multirow[t]{2}{*}{3} & 1.32 & 4.78 & $37.30 \%$ & 7.12 & 0.45 & -0.11 & -0.15 \\
\hline & & & & & & {$[-1.1]$} & {$[-1.42]$} \\
\hline \multirow[t]{2}{*}{$3-1$} & -0.12 & & & & & -0.16 & -0.22 \\
\hline & {$[-0.6]$} & & & & & {$[-0.82]$} & {$[-1.13]$} \\
\hline
\end{tabular}




\section{Conclusion}

The idiosyncratic volatility puzzle is still an open research question. It is not clear why portfolios sorted by increasing IVOL have lower expected returns. Hou and Loh (2016) find that many real explanations explain less than $10 \%$ of the puzzle. As far as I know, this paper is the first one to investigate the IVOL puzzle driver by using the indegree based on the Granger causality network. The contribution can be split in two parts: The first part outlines that network indegree based on the Granger causality affects stocks returns; stocks having higher indegree have lower expected returns. Once created the factor $I N D$ given as the difference of the $3^{t h}-1^{s t}$ tercile, it affects the cross-section of stocks returns having a negative price of risk: insurance for investors. This factor is relevant for explaining the covariation of the abnormal returns of the 25 portfolios sorted by size and Book-to-market. The Fama and MacBeth (1973) procedure shows evidence in the pricing in 48 industry portfolios but not for 25 portfolios sorted by size and Book-to-market. In the latter case, $I N D$ is a factor priced for reasons not related to the FVIX Ang et al. (2006) i.e., the mimicking factor portfolio replicated in the appendix A. Stocks having higher indegree hold lower contemporaneous IVOL indicating that indegree could help investors to increase the information for that stocks. The reasons why the portfolios having higher indegree have lower expected returns should be deepened, from one side can be related to the nature of the Granger causality stocks having higher indegree are at the same time the most predictable stocks Baker and Wurgler (2006), on the other hand, can reveal some potential trading strategies see Cohen-Cole et al. (2014). The other centrality measures, except indegree, described in section 3, have weaker and inconsistent relations with expected returns.

Although many other robustness checks should be done to support the thesis that IND is a risk factor priced by the market as also to extend the sample time interval until 2016, the second part of the paper shows that IVOL is priced for reasons not related to IND. However, the relation between IVOL and IND is negative that is the second contribution of the paper. Portfolios having higher and increasing IVOL have higher negative factor exposure to IND. 


\section{References}

Acemoglu, D., Carvalho, V. M., Ozdaglar, A., and Tahbaz-Salehi, A. (2012). The network origins of aggregate fluctuations. Econometrica, 80(5):1977-2016.

Ahern, K. R. (2013). Network centrality and the cross section of stock returns. Available at SSRN 2197370.

Ang, A., Hodrick, R. J., Xing, Y., and Zhang, X. (2006). The cross-section of volatility and expected returns. The Journal of Finance, 61(1):259-299.

Ang, A., Hodrick, R. J., Xing, Y., and Zhang, X. (2009). High idiosyncratic volatility and low returns: International and further us evidence. Journal of Financial Economics, 91(1):1-23.

Baker, M. and Wurgler, J. (2006). Investor sentiment and the cross-section of stock returns. The Journal of Finance, 61(4):1645-1680.

Bakshi, G., Cao, C., and Chen, Z. (2000). Pricing and hedging long-term options. Journal of Econometrics, 94(1):277-318.

Bakshi, G. and Kapadia, N. (2003). Delta-hedged gains and the negative market volatility risk premium. Review of Financial Studies, 16(2):527-566.

Bakshi, G., Kapadia, N., and Madan, D. (2003). Stock return characteristics, skew laws, and the differential pricing of individual equity options. The Review of Financial Studies, 16(1):101143.

Billio, M., Getmansky, M., Lo, A. W., and Pelizzon, L. (2012). Econometric measures of connectedness and systemic risk in the finance and insurance sectors. Journal of Financial Economics, 104(3):535-559.

Bonacich, P. (1987). Family and centrality: A family of measures. American Journal of Sociology, 92(5):11701182.

Brandt, M. W., Brav, A., Graham, J. R., and Kumar, A. (2009). The idiosyncratic volatility puzzle: Time trend or speculative episodes? The Review of Financial Studies, 23(2):863-899.

Breeden, D. T., Gibbons, M. R., and Litzenberger, R. H. (1989). Empirical tests of the consumption-oriented capm. The Journal of Finance, 44(2):231-262.

Buraschi, A. and Jackwerth, J. (2001). The price of a smile: Hedging and spanning in option markets. The Review of Financial Studies, 14(2):495-527.

Buraschi, A. and Tebaldi, C. (2017). Asset pricing in network economies with systemic risk.

Campbell, J. Y. and Hentschel, L. (1992). No news is good news: An asymmetric model of changing volatility in stock returns. Journal of financial Economics, 31(3):281-318.

Campbell, J. Y., Lettau, M., Malkiel, B. G., and Xu, Y. (2001). Have individual stocks become more volatile? an empirical exploration of idiosyncratic risk. The Journal of Finance, 56(1):143. 
Carhart, M. (1997). On the persistence of mutual fund performance. Journal of Finance, $52: 57-82$.

Carr, P. and Wu, L. (2008). Variance risk premiums. The Review of Financial Studies, 22(3):1311-1341.

Chen, Z. and Petkova, R. (2012). Does idiosyncratic volatility proxy for risk exposure? Review of Financial Studies, 25(9):2745-2787.

Chernov, M. and Ghysels, E. (2000). A study towards a unified approach to the joint estimation of objective and risk neutral measures for the purpose of options valuation. Journal of financial economics, 56(3):407-458.

Cohen-Cole, E., Kirilenko, A., and Patacchini, E. (2014). Trading networks and liquidity provision. Journal of Financial Economics, 113(2):235-251.

Coval, J. D. and Shumway, T. (2001). Expected option returns. The journal of Finance, 56(3):983-1009.

Cujean, J. and Hasler, M. (2017). Why does return predictability concentrate in bad times. Technical report, Journal of Finance, Forthcoming.

Diebold, F. X. and Yilmaz, K. (2014). On the network topology of variance decompositions: measuring the connectedness of financial firms. Journal of Econometrics, 182(1):119-134.

Eraker, B., Johannes, M., and Polson, N. (2003). The impact of jumps in volatility and returns. The Journal of Finance, 58(3):1269-1300.

Ewens, M., Jones, C. M., and Rhodes-Kropf, M. (2013). The price of diversifiable risk in venture capital and private equity. Review of Financial Studies, 26(8):1854-1889.

Fama, E. and French, K. (1993). Common risk factors in the returns of stocks and bonds. Journal of Financial Economics, 33(3-53).

Fama, E. F. and MacBeth, J. D. (1973). Risk, return, and equilibrium: Empirical tests. Journal of political economy, 81(3):607-636.

French, K. R., Schwert, G. W., and Stambaugh, R. F. (1987). Expected stock returns and volatility. Journal of financial Economics, 19(1):3-29.

$\mathrm{Fu}, \mathrm{F}$. (2009). Idiosyncratic risk and the cross-section of expected stock returns. Journal of Financial Economics, 91(1):24-37.

Gabaix, X. (2011). The granular origins of aggregate fluctuations. Econometrica, 79(3):733-772.

Garcia, D. (2013). Sentiment during recessions. The Journal of Finance, 68(3):1267-1300.

Granger, C. W. J. (1969). Investigating causal relations by econometric models and cross spectral methods. Econometrica, 37:424-438. 
Gridold, R. and Kahn, R. (1999). Active portfolio management: A quatitative approach for producing superior returns and controlling risk.

Herskovic, B. (2015). Networks in production: Asset pricing implications. Browser Download This Paper.

Herskovic, B., Kelly, B., Lustig, H., and Van Nieuwerburgh, S. (2016). The common factor in idiosyncratic volatility: Quantitative asset pricing implications. Journal of Financial Economics, 119(2):249-283.

Hou, K. and Loh, R. K. (2016). Have we solved the idiosyncratic volatility puzzle? Journal of Financial Economics, 121(1):167-194.

Jackwerth, J. C. and Rubinstein, M. (1996). Recovering probability distributions from option prices. The Journal of Finance, 51(5):1611-1631.

Kelly, B., Lustig, H., and Nieuwerburgh, S. V. (2013). Firm volatility in granular networks. Mimeo. Booth School of Business, UCLA-Anderson and Stern School of Business.

Lamont, O., Polk, C., and Saaá-Requejo, J. (2001). Financial constraints and stock returns. The Review of Financial Studies, 14(2):529-554.

Lucas, R. E. (1977). Understanding business cycles. In Carnegie-Rochester conference series on public policy, volume 5, pages 7-29. Elsevier.

Malkiel, B. G. and Xu, Y. (2002). Idiosyncratic risk and security returns. University of Texas at Dallas (November 2002).

Merton, R. C. (1987). A simple model of capital market equilibrium with incomplete information. The journal of finance, 42(3):483-510.

Newey, W. and West, K. (1987). A simple positive definite, het-eroskedasticity and autocorrelation consistent covariance matrix, econo-metrica 55: 703-705. MathSciNet MATH.

Newman, M. (2010). Networks: an introduction. Oxford university press.

Pan, J. (2002). The jump-risk premia implicit in options: Evidence from an integrated timeseries study. Journal of financial economics, 63(1):3-50.

Pástor, L. and Stambaugh, R. F. (2003). Liquidity risk and expected stock returns. Journal of Political economy, 111(3):642-685.

Ross, S. A. (1976). The arbitrage theory of capital asset pricing. Journal of economic theory, $13(3): 341-360$.

Shanken, J. (1992). On the estimation of beta-pricing models. The review of financial studies, $5(1): 1-33$.

Stambaugh, R. F., Yu, J., and Yuan, Y. (2015). Arbitrage asymmetry and the idiosyncratic volatility puzzle. The Journal of Finance, 70(5):1903-1948. 
Stewart, S. D., Piros, C. D., and Heisler, J. (2011). Running money: Professional portfolio management. McGraw-Hill Irwin. 


\section{Appendix}

\section{A Aggregate and idiosyncratic volatility puzzle}

This section reports the results of Ang et al. (2006) replication, the pool of stocks and the time interval is the same I used to investigate the puzzle causes. According to the authors, the stocks are ordered and grouped in quintile by looking at the sensitivity of the innovations on the aggregate volatility $\Delta V I X$ following this equation:

$$
r_{i t}=\alpha_{i}+\beta_{M K T} M K T_{t}+\beta_{\Delta V I X} \Delta V I X_{t}+\epsilon_{t}
$$

where $r_{i}$ indicates the excess return of the $i_{t h}$ stock, $\beta_{M K T}$ measures the sensitivity on the market CRSP index, $\beta_{\Delta V I X}$ represents the exposure on the change of the aggregate volatility risk. The figure (A.4) shows the quintile portfolios cumulative returns sorted with respect to the exposition on the aggregate volatility of the previous month. The higher is the exposition on the aggregate volatility risk the lower are the portfolios' returns. Portfolios gathering stocks having lower exposure on the $\Delta V I X$ outperform portfolio having higher exposure to the change of the delta volatility index. 


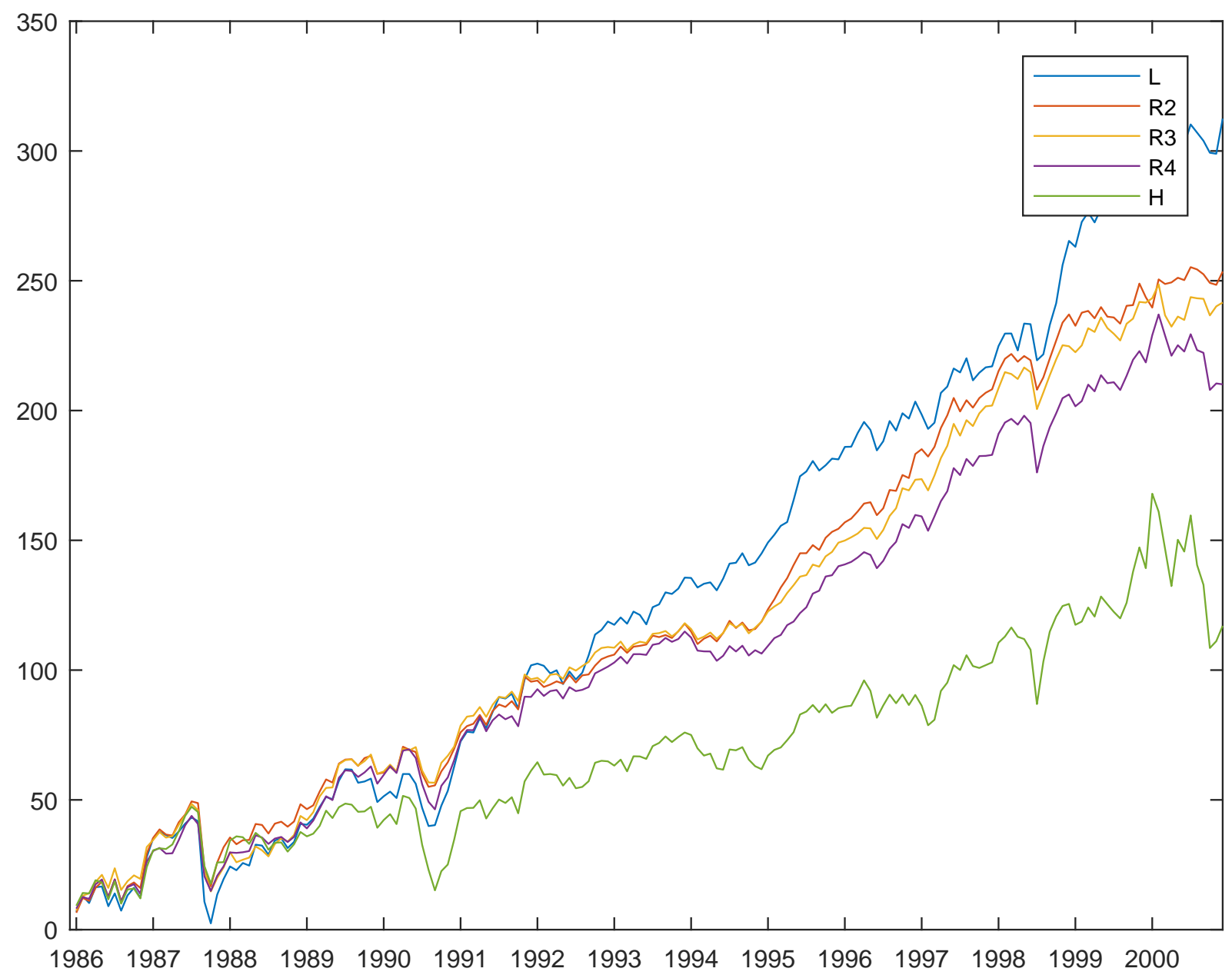

Figure A.4: Quintile portfolios cumulative returns sorted by $\Delta V I X$. The figure reports the cumulative returns of the five quintile portfolios, sorted to $\beta_{V I X}$ the previous month. Each portfolio is value-weighted. L represents the portfolio made up with stocks having the lowest exposition on the aggregate volatility risk, R2 is the second quintile, R3 is the third quintile, $\mathrm{R} 4$ is the fourth quintile, $\mathrm{H}$ is the portfolio built with stocks having the highest exposure on the aggregate volatility risk.

What is shown in figure (A.4) is coherent with the second column of the table (A.14). The reason of the replication of the table (A.14) is to understand how much the results are close to Ang et al. (2006) paper in order to start the second analysis investigating if IVOL can be explained by using indegree based on the network estimated with the Granger causality test. Also, it is worth to understand if the pricing of indegree (assuming to be a risk factor) takes place in the same dimension of FVIX.

The first column of table (A.14) includes the portfolio quantile sorted by the exposure to $\Delta V I X$, grouped in quintile. The second and the third column represent respectively totally returns value weighted average and the standard deviation. The monthly average is roughly $1.74 \%$ for the lowest quintile and decreases until $0.65 \%$ for the highest quintile. They are computed by selecting the stocks according to with equation (18) by looking at the exposition to $\Delta V I X$ of daily returns of the previous month. Market capitalization at the end of the last month is used as the weight for computing the value-weighted portfolio. Portfolios co-varying more with the change volatility risk have lower expected returns. 
The average market share of the quintile portfolios is calculated for each month as the ratio between the market capitalization of each quintile portfolio and the market capitalization of all portfolios. Size is the logarithm of the total market portfolio capitalization averaged by month. B/M (Book-to-Market) reports for each quintile portfolio the ratio between the market value and the book value at the end of the month. Firms having low market capitalization are in the extreme quintiles suggesting that the small size firms do not drive high exposition to the change of the aggregate volatility. Companies having higher market capitalization are located in the middle quantiles. Alpha columns with respect to the CAPM and three-factor model Fama and French (1993) present a decreasing pattern as soon as the exposition on $\Delta V I X$ increases, they are significant for the $\mathbf{5}$ and $\mathbf{5 - 1}$ portfolios quintile. The alpha coefficients significance indicates that a possible omitted risk factor can be present; CAPM and Fama and French (1993) are not enough to explain the cross-section of the stock returns.

To reduce the noise in the estimates, the authors compute according to Breeden et al. (1989) and Lamont et al. (2001), the mimicking portfolio FVIX of the aggregate volatility risk $\Delta V I X$ , as in the equation (19).

$$
\Delta V I X_{t}=a+b^{\prime} X_{t}+e_{t}
$$

$a$ is the intercept and $X_{t}$ are the excess returns of the quintiles portfolios according to (18). For each month, the estimation of $\hat{b}$ according to the equation (19) is $F V I X_{t}=\hat{b}^{\prime} X_{t}$. Once defined the $F V I X$, they selected the stocks with respect to the factor mimicking aggregate volatility risk FVIX and modifying the equation (18) that assumes this form.

$$
r_{i t}=\alpha_{i}+\beta_{M K T} M K T_{t}+\beta_{F V I X} F V I X_{t}+\epsilon_{t}
$$

$r_{i}$ indicates the excess return of the $i_{t h}$ stock, $\beta_{M K T}$ measures the sensitivity on the Market CRSP index, $\beta_{F V I X}$ is the sensitivity on FVIX the mimicking factor portfolio of $\triangle V I X$.

In the table (A.14) columns $\beta_{\Delta V I X}$ and $\beta_{F V I X}$ report the value-weighted average of the exposition to $\triangle V I X$ and $F V I X$ factor for each quintile portfolio, according to (18) and (20). As can be observed, both columns have the patterns, and in particular the portfolio sorted by $\triangle V I X$ exposures, are more two times higher than the portfolios sorted by $F V I X$.

Next month Formation $\beta_{\Delta V I X}$ displays the value-weighted ex-post beta formation on the aggregate volatility risk. The computation procedure is the following according to the authors: Once selected the stocks about the exposure on aggregate volatility risk innovations at the month $t$, they compute the forecast of the daily returns quintile portfolio at the month $t+1$. The post-formation beta is computed by using the equation (18) at the time $t+1$ and using quintile portfolio return at time $t+1$ as dependent variable. The results are averaged. The replication finds as the authors Ang et al. (2006) that ex-post exposure on aggregate volatility risk innovations is drastically lower than ex-ante exposure, but the pattern is still increasing. The last column Full sample post-formation reports the exposure on the regression monthly based between the Fama and French (1993) model augmented by the FVIX monthly observation and the ex-post quantile portfolio returns ordered concerning the past loading on $\Delta V I X$ according to $(18)$. 
Table A.14: Portofolios Sorted by exposition on the aggregate volatility. Value weighted portfolio quantile total returns sorted by the exposition on the $\beta_{\triangle V I X}$ as in equation (18). The statistics Mean, and Standard Deviation are relative to the total portfolio returns monthly percentage. Size defines the average log stock market capitalization within the quintile portfolios and $B / M$ average of the Book-to-Market ratio. The Alpha columns report the Jensens' alpha with respect to the CAPM and the Fama and French (1993). The columns $\beta_{\Delta V I X}$ and $\beta_{F V I X}$ represent the exposure to $\Delta$ VIX, and FVIX averaged for the whole sample. Finally, $\beta_{\Delta V I X}$ reports the next month exposure on $\Delta$ VIX averaged across the month, and $\beta_{F V I X}$ defines the post-formation of all sample by using daily portfolios returns. Robust Newey and West (1987) t-statistics are reported in square brackets. The sample period is from January 1986 to December 2000.

\begin{tabular}{|c|c|c|c|c|c|c|c|c|c|c|c|}
\hline Rank & Mean & Std Dev. & $\begin{array}{c}\text { Market } \\
\text { Share }\end{array}$ & Size & $\mathrm{B} / \mathrm{M}$ & $\begin{array}{c}\text { CAPM } \\
\text { Alpha }\end{array}$ & $\begin{array}{l}\text { FF-3 } \\
\text { Alpha }\end{array}$ & $\begin{array}{c}\text { Pre } \\
\text { Formation } \\
\beta_{\Delta V I X}\end{array}$ & $\begin{array}{c}\text { Pre } \\
\text { Formation } \\
\beta_{F V I X}\end{array}$ & $\begin{array}{c}\text { Next } \\
\text { Month } \\
\text { Formation } \\
\beta_{\Delta V I X}\end{array}$ & $\begin{array}{c}\text { Full } \\
\text { Sample } \\
\text { Post } \\
\text { Formation } \\
\beta_{F V I X}\end{array}$ \\
\hline \multirow[t]{2}{*}{1} & 1.74 & 5.66 & $9.71 \%$ & 5.89 & 0.45 & 0.27 & 0.32 & -3.97 & -1.35 & -0.044 & -5.04 \\
\hline & & & & & & [1.41] & {$[1.65]$} & & & & {$[-15.76]$} \\
\hline \multirow[t]{2}{*}{2} & 1.41 & 4.45 & $28.80 \%$ & 7.10 & 0.45 & 0.16 & 0.08 & -1.41 & -0.43 & 0.005 & -0.94 \\
\hline & & & & & & {$[1.51]$} & {$[0.91]$} & & & & {$[-2.43]$} \\
\hline \multirow[t]{2}{*}{3} & 1.34 & 4.42 & $30.85 \%$ & 7.18 & 0.46 & 0.10 & 0.05 & 0.38 & 0.03 & 0.006 & -0.26 \\
\hline & & & & & & {$[0.95]$} & {$[0.6]$} & & & & {$[-0.85]$} \\
\hline \multirow[t]{2}{*}{4} & 1.17 & 4.81 & $23.25 \%$ & 6.87 & 0.46 & -0.13 & -0.12 & 1.91 & 0.49 & -0.004 & 0.28 \\
\hline & & & & & & {$[-1.38]$} & {$[-1.19]$} & & & & {$[0.77]$} \\
\hline \multirow[t]{2}{*}{5} & 0.65 & 6.67 & $7.39 \%$ & 5.67 & 0.46 & -0.87 & -0.52 & 4.73 & 1.42 & 0.061 & 2.33 \\
\hline & & & & & & {$[-3.19]$} & {$[-2.32]$} & & & & {$[3.52]$} \\
\hline \multirow[t]{2}{*}{$5-1$} & -1.09 & & & & & -1.55 & -1.04 & & & & \\
\hline & {$[-3.07]$} & & & & & {$[-4.29]$} & {$[-3.61]$} & & & & \\
\hline
\end{tabular}


The contribution of Ang et al. (2006) is to show that the change in aggregate volatility risk is a price factor. In particular, $F V I X$, the mimicking portfolio of the $\Delta V I X$ has a negative price of risk and significant. ${ }^{17}$. Table A.15 displays the results by combining the FVIX with Fama and French (1993), Carhart (1997), and Pástor and Stambaugh (2003) factors.

Table A.15: Fama-MacBeth (1973) Factor Premiums The table shows the premium computed on the 25 portfolios sorted on the Market exposure $\beta_{M K T}$ and $\beta_{\Delta V I X}$ by using Fama and MacBeth (1973) procedure. The first column reports the Fama and French (1993) factors premium and the mimicking factor portfolio premium. The second column adds the Carhart (1997) factors premium. The third column adds the Pástor and Stambaugh (2003) factors premium. In all cases the FVIX premium is always significant.

\begin{tabular}{|c|c|c|c|c|c|c|}
\hline & I & II & III & IV & $\mathrm{V}$ & VI \\
\hline \multirow[t]{2}{*}{ Constant } & 2.19 & 2.30 & 2.00 & - & - & - \\
\hline & {$[3.53]$} & {$[2.87]$} & {$[2.17]$} & - & - & - \\
\hline \multirow[t]{2}{*}{ MKT } & -0.83 & -0.93 & -0.64 & 1.32 & 1.29 & 1.28 \\
\hline & {$[-1.35]$} & {$[-1.19]$} & {$[-0.72]$} & {$[3.81]$} & {$[3.73]$} & {$[3.67]$} \\
\hline \multirow[t]{2}{*}{ FVIX } & -2.53 & -2.57 & -2.89 & -3.56 & -2.97 & -3.62 \\
\hline & {$[-2.77]$} & {$[-2.70]$} & {$[-2.71]$} & {$[-2.79]$} & {$[-2.56]$} & {$[-2.57]$} \\
\hline \multirow[t]{2}{*}{ SMB } & 2.52 & 2.53 & 2.55 & 2.21 & 2.27 & 2.41 \\
\hline & {$[9.76]$} & {$[9.48]$} & {$[9.37]$} & {$[4.74]$} & {$[4.86]$} & {$[4.50]$} \\
\hline \multirow[t]{2}{*}{ HML } & -0.92 & -0.91 & -0.90 & -0.16 & -0.51 & -0.62 \\
\hline & {$[-3.33]$} & {$[-3.13]$} & {$[-3.06]$} & {$[-0.37]$} & {$[-1.16]$} & {$[-1.27]$} \\
\hline \multirow[t]{2}{*}{ UMD } & & 0.88 & 0.55 & & -0.66 & -0.98 \\
\hline & & {$[1.15]$} & {$[0.60]$} & & {$[-0.83]$} & {$[-1.05]$} \\
\hline \multirow[t]{2}{*}{ LIQ } & & & 0.00 & & & 0.01 \\
\hline & & & {$[0.52]$} & & & {$[1.07]$} \\
\hline $\operatorname{Adj} R^{\wedge} 2$ & $89.1 \%$ & $88.61 \%$ & $88.33 \%$ & $82.3 \%$ & $83.65 \%$ & $85.27 \%$ \\
\hline $\begin{array}{c}\text { Shanken } \\
\text { Correction }\end{array}$ & $\mathrm{N}$ & $\mathrm{N}$ & $\mathrm{N}$ & $\mathrm{Y}$ & $\mathrm{Y}$ & $\mathrm{Y}$ \\
\hline
\end{tabular}

From the other side if the Fama and French (1993) is the correct model and the FVIX is a priced factor then the omitted factor should be shown by looking at the residuals of the equation (21).

$$
r_{i t}=\alpha_{i}+\beta_{M K T} M K T_{t}+\beta_{S M B} S M B_{t}+\beta_{H M L} H M L_{t}+\epsilon_{t}
$$

Although the mimicking tracking portfolio of aggregate volatility risk FVIX is a risk factor with negative premium, Ang et al. (2006) showed that the cause IVOL puzzle is not related to the omitted factor FVIX. Portfolios monthly returns are computed by ordering stocks according to the total volatility and IVOL with respect to the equation (21) at the previous month, daily observations. The table (A.16) indicates the average and standard deviation of the value-weighted quintile portfolio returns. The behavior observed by the authors as in table (A.16) states that high idiosyncratic risk portfolios have a lower expected return. At the contrary in table (A.14) small size firms have higher IVOL and total volatility, as reported by the Market share column. The last two columns display the CAPM and Fama and French (1993) alphas, relative to the quintile portfolios monthly returns. The pattern is decreasing, and according

\footnotetext{
${ }^{17}$ The results are with and without the significance correction proposed by Shanken (1992). In this part of the paper, the first goal is to obtain results as close as possible to the Ang et al. (2006)
} 
to the $\alpha$ 's relative to CAPM and Fama and French (1993) in panel B table (A.16), there is an omitted factor not related to FVIX, i.e., the mimicking factor portfolio of the aggregate volatility changes. The causes of this decreasing pattern puzzles the researchers, according to Ross (1976) the IVOL risk is not priced, because this kind of risk can be diversified. ${ }^{18}$ If the idiosyncratic risk is not priced then the expected returns of stocks would not evidence any pattern with respect to the portfolios ordered by idiosyncratic volatility, and moreover the alphas of model CAPM and Fama and French (1993) reported in the last two columns (A.16) would be not significantly different from zero.

\footnotetext{
${ }^{18}$ Ross showed that the IVOL risk is diversifiable by increasing the number of stocks held in the portfolio. Assuming that the assets are not cross-correlated they have the same variance, then the idiosyncratic risk tend to zero when the number of assets tends to infinity.
} 
Table A.16: Portfolio sorted by total (idiosyncratic) volatility Panel A (Panel B). The statistics are relative to the quantile portfolios ordered with respect to the total volatily (IVOL) of equation (21). The value weighted average and the standard deviation are relative to the returns monthly based. Market share defines the market capitalization of the portfolio, Size is computed as logarithm of stock market capitalization and $\mathrm{B} / \mathrm{M}$ is the Book-to-Market ratio average. Alpha columns represent the intercept by regressing the porfolio returns with the the CAPM and the Fama and French (1993) model. The time interval of the analysis is from January 1986 to December 2000 as Ang et al. (2006). Robust Newey and West (1987) t-statistics are reported in square brackets.

\begin{tabular}{|c|c|c|c|c|c|c|c|}
\hline \multicolumn{8}{|c|}{ Portofolios Sorted by Total Volatility } \\
\hline Rank & Mean & Std Dev. & $\begin{array}{l}\text { Market } \\
\text { Share }\end{array}$ & Size & $\mathrm{B} / \mathrm{M}$ & $\begin{array}{c}\text { CAPM } \\
\text { Alpha }\end{array}$ & $\begin{array}{l}\text { FF-3 } \\
\text { Alpha }\end{array}$ \\
\hline \multirow[t]{2}{*}{1} & 1.33 & 3.92 & $49.79 \%$ & 7.63 & 0.47 & 0.17 & -0.00 \\
\hline & & & & & & {$[1.37]$} & {$[-0.07]$} \\
\hline \multirow[t]{2}{*}{2} & 1.42 & 4.68 & $31.94 \%$ & 7.20 & 0.44 & 0.15 & 0.05 \\
\hline & & & & & & {$[1.39]$} & {$[0.61]$} \\
\hline \multirow[t]{2}{*}{3} & 1.40 & 5.96 & $11.80 \%$ & 6.16 & 0.44 & -0.01 & 0.14 \\
\hline & & & & & & {$[-0.09]$} & {$[1.00]$} \\
\hline \multirow[t]{2}{*}{4} & 1.03 & 7.79 & $4.79 \%$ & 5.22 & 0.44 & -0.57 & -0.13 \\
\hline & & & & & & {$[-1.78]$} & {$[-0.59]$} \\
\hline \multirow[t]{2}{*}{5} & -0.11 & 9.34 & $1.68 \%$ & 4.10 & 0.44 & -1.78 & -1.25 \\
\hline & & & & & & {$[-4.21]$} & {$[-4.11]$} \\
\hline \multirow[t]{2}{*}{$5-1$} & -1.44 & & & & & -1.96 & -1.24 \\
\hline & {$[-2.08]$} & & & & & {$[-3.72]$} & {$[-3.44]$} \\
\hline \multicolumn{8}{|c|}{ Portofolios Sorted by Idiosyncratic Volatility } \\
\hline Rank & Mean & Std Dev. & $\begin{array}{l}\text { Market } \\
\text { Share }\end{array}$ & Size & $\mathrm{B} / \mathrm{M}$ & $\begin{array}{c}\text { CAPM } \\
\text { Alpha }\end{array}$ & $\begin{array}{l}\text { FF-3 } \\
\text { Alpha }\end{array}$ \\
\hline \multirow[t]{2}{*}{1} & 1.40 & 4.16 & $61.42 \%$ & 7.87 & 0.44 & 0.19 & 0.03 \\
\hline & & & & & & {$[1.63]$} & {$[0.36]$} \\
\hline \multirow[t]{2}{*}{2} & 1.33 & 4.83 & $24.45 \%$ & 6.94 & 0.45 & 0.04 & 0.02 \\
\hline & & & & & & {$[0.47]$} & {$[0.22]$} \\
\hline \multirow[t]{2}{*}{3} & 1.31 & 6.21 & $8.96 \%$ & 5.92 & 0.45 & -0.16 & 0.02 \\
\hline & & & & & & {$[-0.85]$} & {$[0.20]$} \\
\hline \multirow[t]{2}{*}{4} & 0.72 & 7.74 & $3.81 \%$ & 5.03 & 0.46 & -0.85 & -0.44 \\
\hline & & & & & & {$[-3.10]$} & {$[-2.68]$} \\
\hline \multirow[t]{2}{*}{5} & -0.24 & 9.17 & $1.36 \%$ & 3.97 & 0.46 & -1.80 & -1.29 \\
\hline & & & & & & {$[-4.04]$} & {$[-4.54]$} \\
\hline \multirow[t]{2}{*}{$5-1$} & -1.47 & & & & & -2.00 & -1.32 \\
\hline & {$[-2.37]$} & & & & & {$[-3.70]$} & {$[-3.91]$} \\
\hline
\end{tabular}




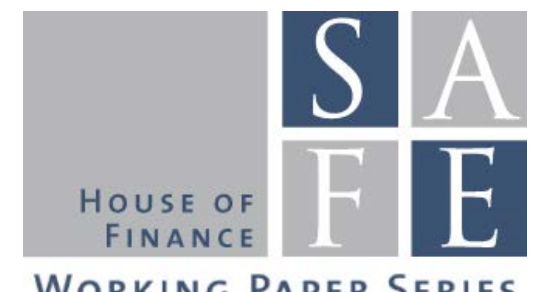

WORKING PAPER SERIES

\section{Recent Issues}

No. 227 Mila Getmansky, Ravi Jagannathan, Loriana Pelizzon, Ernst Schaumburg, Darya Yuferova

No. 226 Loriana Pelizzon, Marti G. Subrahmanyam, Davide Tomio, Jun Uno

No. 225 Monica Billio, Massimiliano Caporin, Lorenzo Frattarolo, Loriana Pelizzon

No. 224 Giulio Girardi, Kathleen W. Hanley, Stanislava Nikolova, Loriana Pelizzon, Mila Getmansky Sherman

No. 223 Florian Deuflhard

No. 222 Vanessa Endrejat, Matthias Thiemann

No. 221 Axel H. Börsch-Supan, Klaus Härtl, Duarte N. Leite, Alexander Ludwig

No. 220 Yangming Bao, Martin R. Goetz

No. 219 Andreas Hackethal - Christine Laudenbach - Steffen Meyer Annika Weber

No. 218 Florian Hoffmann, Roman Inderst, Marcus Opp

No. 217 Maddalena Davoli, Jia Hou

No. 216 Stefano Colonnello, Giuliano Curatola, Alessandro Gioffré
Stock Price Crashes: Role of Slow-Moving Capital

\section{Central Bank-Driven Mispricing?}

Networks in risk spillovers:

A multivariate GARCH perspective

Portfolio Similarity and Asset Liquidation in the Insurance Industry

Quantifying Inertia in Retail Deposit Markets

Reviving the Shadow Banking Chain in Europe: Regulatory Agency, Technical Complexity and the Dynamics of CoHabitation

Endogenous Retirement Behavior of Heterogeneous Households Under Pension Reforms

Local Peer Effects and Corporate Investment

Client Involvement in Expert Advice Antibiotics in Finance?

Only Time will Tell: A Theory of Deferred Compensation

Financial Literacy and Socialist Education: Lessons from the German Reunification

Pricing Sin Stocks: Ethical Preference vs. Risk Aversion 